\title{
Reciclagem de borracha de pneu e resíduo de concreteira na produção de tijolos de concreto: dosagem e otimização
}

\author{
Recycling of tire rubber and concrete residue \\ in the production of concrete bricks: \\ dosing and optimization
}

Ruvier Rodrigues Pereira ${ }^{1}$, Heber Martins de Paula ${ }^{2}$, Walter Batista Bonfim ${ }^{3}$ Iandra de Almeida Corrêa e Silva ${ }^{4}$, Henrique Senna Diniz Pinto ${ }^{5}$

\footnotetext{
${ }^{1}$ UNA Catalão, Departamento de Engenharia Civil, R. Prof. Paulo de Lima, 100, CEP 75706-725, Catalão, GO, Brasil.

${ }^{2}$ Universidade Federal de Goiás - Regional Catalão, PPG em Modelagem e Otimização - PPGMO e PPG em Engenharia Civil - PPGEC, Av. Dr. Lamartine Pinto de Avelar, 1120, CEP 75704-020, Catalão, GO, Brasil.

${ }^{3}$ Universidade Federal de Goiás, Laboratório de Inovação Tecnológica em Construção Civil, Av. Universitária, 1488. CEP 74605-220, Goiânia, GO, Brasil.

${ }^{4}$ Universidade Federal de Goiás - Regional Catalão, Engenharia Civil, Av. Dr. Lamartine Pinto de Avelar, 1120, CEP 75704-020, Catalão, GO, Brasil.

${ }^{5}$ Universidade Federal de Goiás - Regional Catalão, Engenharia de Minas, Av. Dr. Lamartine Pinto de Avelar, 1120, CEP 75704-020, Catalão, GO, Brasil.

e-mail: ruvierrodrigues@hotmail.com, heberdepaula@ufg.br,walter-bonfim@hotmail.com, iandra140@gmail.com, hsennadiniz@hotmail.com
}

\begin{abstract}
RESUMO
$\mathrm{O}$ volume de resíduos sólidos produzido vem aumentando de modo desordenado e prejudicial à natureza, uma vez que não são dados a ele fins adequados. Como resíduos passíveis de utilização na fabricação de tijolos de concreto tem-se a borracha de pneus, grande causadora de problemas ambientais, e o resíduo cimentício gerado em usinas de concreto, denominado de Lama Residual do Concreto (LRC). O objetivo geral deste estudo foi determinar um traço de concreto para produção de tijolos que contivesse maiores porcentagens de resíduos de usinas de concreto e de borracha de pneu, conjuntamente. Para tanto, foi utilizado o Delineamento Composto Central Rotacional como planejamento experimental e os dados avaliados via Metodologia de Superfície de Resposta, sendo o granulado de borracha em substituição ao agregado e a lama residual do concreto seca (LRC-S) substituindo o cimento. Foram realizados a caracterização físico-química dos agregados, ensaio de resistência à compressão e absorção de água dos tijolos. Os resultados mostraram que é viável utilizar a LRC-S e o granulado de borracha de pneu, obtendo um traço ótimo que apresenta resistência à compressão de 7,9 MPa e 8,8\% de absorção de água, atendendo o limite de $3 \mathrm{MPa}$ de resistência à compressão e 10\% de absorção de água da ABNT NBR 6136 de 2014. O traço ótimo foi produzido com 4\% de borracha e $15 \%$ de LRC-S, em substituição ao agregado e ao cimento, respectivamente. Ressalta-se que quanto maior a porcentagem de borracha, menor será a resistência à compressão e maior será a absorção de água, sendo que o limite de substituição da borracha é dependente do agregado empregado, das condições de moldagem e do traço utilizado.
\end{abstract}

Palavras-chave: Tijolo de concreto, Resíduos de borracha de pneu, Lama Residual de Concreto, Planejamento experimental.

\section{ABSTRACT}

The volume of solid waste produced has been increasing in a disorderly and damaging way to nature, since it is not given adequate purposes. As waste that can be used in the manufacture of concrete bricks, there is tire rubber, a major cause of environmental problems, and the cementitious waste generated in concrete plants, called Concrete Sludge Waste (CSW). The general objective of this study will then be to determine a concrete mix for brick production that contains higher percentages of concrete sludge waste and tire rubber gran- 
ulate, together. For this purpose, the Central Composite Delineation of Rotational was used as experimental planning and the data evaluated via Response Surface Methodology, with the waste tire rubber granulate replacing the aggregate and the Concrete Sludge Waste in its dry state (CSW-S) to the cement. The physicalchemical characterization of the aggregates, compressive strength and water absorption of the bricks were carried out. The results showed that it is feasible to use the CSW-S and the waste tire rubber granulate, obtaining an optimal trace that presents compressive strength of $7.9 \mathrm{MPa}$ and $8.8 \%$ of water absorption, meeting the limit of $3 \mathrm{MPa}$ of compressive strength and 10\% water absorption of ABNT NBR 6136:2014. The optimum line was produced with $4 \%$ rubber and $15 \%$ LRC-S, replacing aggregate and cement, respectively. It is noteworthy that the higher the percentage of rubber, the lower the resistance to compression and the greater the water absorption, being that the limit of replacement of the rubber depends on the aggregate used, the molding conditions and the line used.

Keywords: Concrete brick, Waste tire rubber, Concrete Sludge Waste, Experimental design.

\section{INTRODUÇÃO}

Um dos setores responsáveis por provocar grande impacto ambiental é o da construção civil, pois ele é responsável pelo elevado consumo de matéria-prima e produção de grande volume de resíduos. De acordo com CARELI [1], a indústria da construção civil consome, em média, 50\% dos recursos naturais, e nas cidades brasileiras, $60 \%$ dos resíduos gerados são provindos do setor da construção civil.

Segundo FREIRE e BERALDO [2], diante da grande geração de resíduos sólidos, o reuso destes materiais se tornou uma alternativa para seu controle e descarte. Ao longo dos anos, alguns estudos já vêm sendo realizados para uso dessas matérias-primas alternativas ou não convencionais na construção civil. Assim, com a substituição da matéria-prima por resíduos, é possível reduzir a quantidade de recursos naturais retirados do meio ambiente, bem como a quantidade de resíduos descartados.

Um dos sistemas amplamente adotados na construção civil é o uso de blocos de concreto para execução de alvenaria, seja ela com função estrutural ou não. Tais blocos são compostos basicamente de cimento, agregados e água, e adotar em sua composição parcelas de resíduos traria grandes benefícios ao meio ambiente. Uma outra opção para substituição dos blocos vazados de concreto na alvenaria é o uso de tijolos de concreto, que ainda não são normatizados, e que foram focos desse estudo.

Um resíduo passível de se utilizar na fabricação de blocos ou tijolos é a borracha de pneus, grande causador de problemas ambientais. Os pneus inúteis ou inservíveis são de difícil descarte, além do que, segundo MONTEIRO et al. [3], muitos são os problemas gerados pela sua disposição inadequada, podendo causar proliferação de doenças, instabilidade de solos e a sua incineração gera grande quantidade de materiais particulados e gases tóxicos.

Além dos pneus inservíveis, tem-se os pneus ditos servíveis, que de acordo com LAGARINHOS e TENÓRIO [4] são aqueles que podem ser vendidos no comércio como pneus de meia vida ou ainda serem submetidos a reforma de sua estrutura. Como método de recuperação pode-se destacar o processo de recauchutagem, que segundo FIORITI [5], é o processo onde é realizada uma raspagem das bandas de rodagem do pneu para posterior restabelecimento das mesmas.

O processo de recauchutagem é utilizado em cerca de $70 \%$ dos veículos de carga no Brasil, pois pode aumentar a vida útil do pneu em até $40 \%$, além de gerar uma economia energética e de matéria-prima de $80 \%$, se comparados com a produção de novos pneus [6]. No entanto, tal processo gera resíduos na forma de granulados, sendo constituído basicamente por borracha. Os resíduos da recauchutagem podem, então, ser utilizados para produção de novos materiais. Com isso há uma redução do volume de resíduos descartados, diminuindo a degradação e poluição do meio ambiente.

SILVA et al [7] avaliaram o uso da borracha de recauchutagem de pneus em pavimentações. Apesar de comprovarem uma redução na resistência axial do concreto com os teores de inserção de borracha de $6 \%$ e $9 \%$ em massa, todos os traços produzidos atingiram valores superiores às normativas de referência indicada para pavimentação de vias de baixo tráfego. Destaca-se também que não houve a necessidade de alteração na relação água/cimento nem a utilização de aditivos durante a produção. Além disso, os autores comprovaram a redução na massa específica e no custo de produção do pavimento.

O uso de granulados de borracha de pneus pode ser feito ainda em substituição de parcelas dos agregados, como a areia e brita, trazendo benefícios para o meio ambiente, como redução de extração de matériaprima e redução de depósitos de pneus [8]. Além disso, o uso da borracha pode melhorar algumas características dos blocos ou tijolos, como reduzir a densidade, melhorar o isolamento térmico e acústico, além de apresentar melhor propriedade de drenagem [9]. 
Entretanto, deve-se atentar a fatores que podem comprometer o desempenho de concretos com resíduo de borracha. WANG et al. [10] destacam que esse material induz fissuras no concreto devido à zona de interface de transição entre o agregado e a matriz cimentícia. De acordo com os autores, o tamanho dos agregados de borracha influencia diretamente o aumento das fissuras nessa interface, sendo mais eficaz a utilização de partículas menores. SIDDIKA et al. [11] também relataram que o tamanho da borracha e a quantidade utilizada influenciam na adesão de ar à mistura e hidrofobicidade da borracha, fatores que aumentam a porosidade e diminuem o peso do concreto com adição desse material.

THOMAS e GUPTA [12] apresentaram uma visão geral de algumas pesquisas publicadas sobre as propriedades do concreto com adição de borracha de pneu. Os estudos mostraram que há um futuro promissor para o uso da borracha como um substituto parcial do agregado em concreto. Tal substituição, porém, afeta diretamente a resistência à compressão, não sendo recomendadas, então, substituições maiores que $20 \%$.

Outro resíduo com grande potencial de se utilizar na fabricação de blocos ou tijolos de concreto é aquele gerado em usinas de concreto. Segundo SEALY et al. [13] há três principais fontes geradoras de resíduos nessas usinas: a lavagem dos balões dos caminhões betoneira ao final de cada dia; a lavagem dos pátios de produção e o retorno de sobras de concreto ou concreto devolvido.

Uma iniciativa relativamente comum nas concreteiras é a utilização das sobras de concreto para realização de melhorias na própria empresa (concretagem do pavimento, confecção de blocos para separação de baias etc.); no entanto, essa ação é limitada, visto que as melhorias na central são finitas [14]. A lavagem de pátios e caminhões gera a chamada água residuária de concreto que, em função de suas características (alta alcalinidade, $\mathrm{pH}$ elevado e alto teor de sólidos), deve passar por um tratamento antes de sua descarga para um sistema público ou, até mesmo, para algum possível reuso [15].

Para a melhora da qualidade da água residuária do concreto, SEALEY et al. [13] e TSIMAS e ZERVAKI [16] apresentam métodos semelhantes. Basicamente, o sistema consiste em direcionar a água residuária a um primeiro tanque, para que ocorra a deposição dos sólidos em seu fundo e o excesso de água transborde para outros dois tanques. A diferença se encontra a partir do terceiro tanque. Enquanto SEALEY et al. [13] sugerem que a água decantada seja reutilizada para lavagem do pátio e dos caminhões betoneira, TSIMAS e ZERVAKI [16] propõem a correção de seu pH para aproximadamente 7 (sete) e sua dissolução em água potável ou subterrânea em proporções pequenas ( 0 a $20 \%)$, para sua reutilização na produção de concreto.

Ao resíduo sólido sedimentado no fundo do primeiro tanque, composto basicamente por agregado residual do concreto original e pasta de cimento, dá-se o nome de Lama Residual de Concreto (LRC) [17]. Periodicamente, é necessário que seja realizada a limpeza dos tanques, esvaziando-os e colocando todo o montante sólido a parte, numa baia de secagem. Após tal procedimento, pode-se dispor o resíduo em aterros sanitários [18]. No entanto, a eliminação e disposição de resíduos sólidos tem se tornado um problema para a sociedade. Nesse contexto, iniciativas como a utilização de resíduos em elementos de concreto podem se apresentar como alternativas viáveis.

Acredita-se, então, que os resíduos sólidos gerados nas usinas de concreto são ricos em materiais cimentícios o que pode viabilizar sua aplicação em substituição à parte do cimento utilizado na produção dos blocos ou tijolos. AUDO, MAHIEUX e TURCRY. [19] salientaram a presença de silicatos de cálcio anidro na LRC, o que demonstra um potencial residual de atividade hidráulica nesse material.

KOU, ZHAN e POON [20] analisaram a utilização da LRC em seu estado seco (LRC-S) como agregado miúdo para a produção de blocos de concreto. Os autores substituíram a areia natural por 25, 50, 75 e $100 \%$ em peso pelo resíduo. Foi verificado que, com o aumento da quantidade de resíduo, houve uma redução da densidade, um aumento da absorção e também acréscimo na resistência à compressão se comparados com os blocos sem resíduo. Vale salientar que os blocos com 50\% de substituição apresentaram as maiores resistências. Os referidos autores atribuíram essa elevação de resistência ao efeito filer e à possibilidade de haver cimento ainda não hidratado no resíduo.

Já WANG et al [21] verificaram as influências da LRC no concreto, e realizaram substituições de 15, 30 e $50 \%$ dos agregados, além de variar a relação a/c. Como resultados houve uma redução da resistência a compressão de até 51,5\% para o traço com substituição de 50\% do agregado graúdo. Os autores justificaram essa diminuição devido a fraca ligação da zona de transição entre os agregados reciclados e a pasta, devido a retenção de água superficial do resíduo, além do que os agregados reciclados apresentaram fissuras, ocasionando a diminuição da resistência à compressão do concreto.

Dessa forma, ao se utilizar conjuntamente a borracha de pneu e o resíduo cimentício como substitutos parciais do agregado e do cimento, respectivamente, é possível obter blocos ou tijolos que atendam as recomendações da ABNT NBR 7170 [22], NBR 8491 [23], NBR 6136 [24]. Com isso, pode-se também reduzir 
os impactos negativos causados pelos resíduos, quando utilizados individualmente, para a produção dos blocos ou tijolos.

Tem-se então, como objetivo deste estudo, determinar um traço de concreto para produção de tijolos que contenha maiores porcentagens de resíduos de usinas de concreto, ou seja, a lama residual do concreto seca (LRC-S) e de borracha de forma conjunta.

\section{MATERIAIS E MÉTODOS}

Verificada a viabilidade de utilização dos resíduos, conforme SILVA et al. [25] e BONFIM et al. [26], foi iniciado o estudo de otimização da quantidade de substituição das duas variáveis independentes: borracha e LRC-S. Para ampliar a avaliação do espaço experimental e reduzir o número de experimentos, foi adotado o Delineamento de Composto Central Rotacional (DCCR).

Após determinar o espaço experimental foram iniciados os ensaios de caracterização química e física dos resíduos, ensaio de compressão simples e absorção de água, que visaram obter um traço de concreto para tijolos com maior porcentagem de substituição do agregado miúdo por borracha e do cimento por LRC-S. As faixas ótimas de substituição foram, então, definidas via Metodologia de Superfície de Resposta (MSR).

Após definir as faixas de substituições ideais foi efetuada a validação dos teores obtidos, através da moldagem de novos tijolos.

\subsection{Materiais}

Os tijolos de concreto com adição de LRC-S e granulado de borracha foram produzidos utilizando o cimento Portland de alta resistência inicial (CP V-ARI). Este tipo de cimento desenvolve sua resistência rapidamente devido ao seu maior grau de moagem e ao teor de silicatos de cálcio acima de 70\% [27]. Em função desta característica, o CP V-ARI é muito utilizado em indústrias de pré-moldados, possibilitando uma rápida desforma dos artefatos de concreto e o reinício do processo produtivo. Já para a função de agregado, o material utilizado foi a areia artificial, também conhecida como "pó de pedra".

Após a coleta dos resíduos, a preparação para sua utilização nesta pesquisa consistiu, em suma, nas seguintes etapas: secagem em estufa, moagem e peneiramento da lama residual de concreto seca (LRC-S) e peneiramento do granulado de borracha. Posteriormente, houve a separação e montagem dos kits de moldagem com a quantidade de material necessária para cada traço (Figura 1).

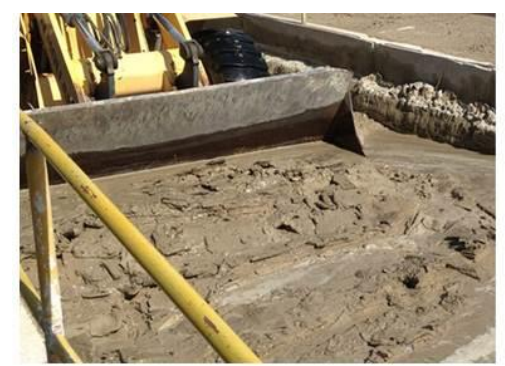

a) Coleta da LRC

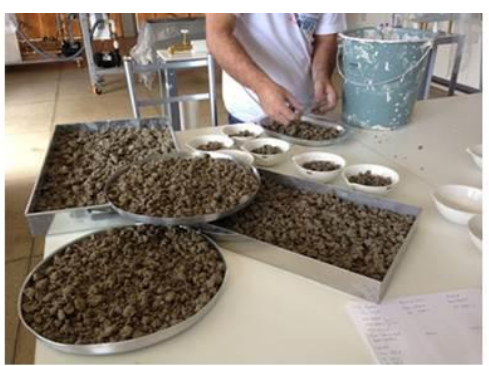

b) Secagem em estufa da LRC

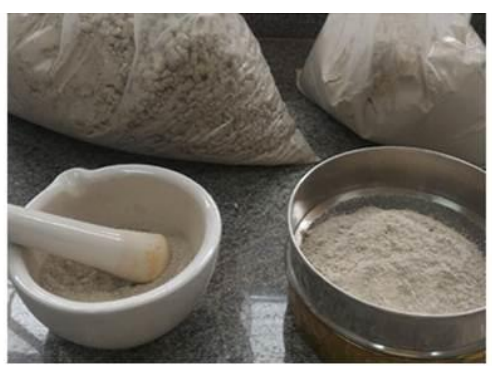

c) Moagem e peneiramento da LRC-S

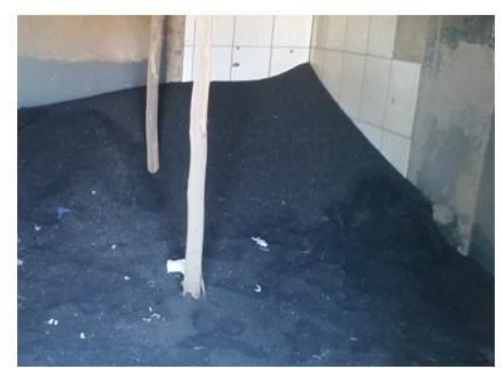

d) Coleta da borracha

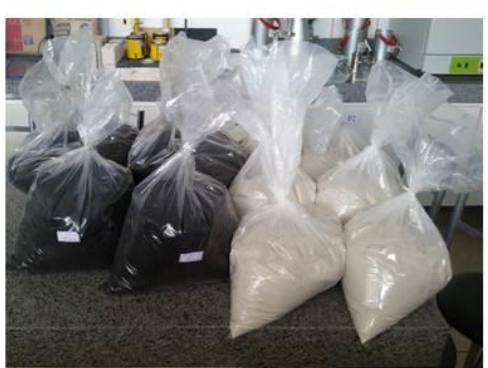

e) Montagem dos kits de moldagem

Figura 1: Processo de obtenção da LRC (a), preparação da LRC-S para utilização (b, c), coleta da borracha (d) e montagem dos kits (e).

A Lama Residual do Concreto (LRC) foi obtida no sistema de tratamento de água residuária de concreto de uma central dosadora. A seleção da usina se deu em função da localização da empresa, do tipo de 
sistema de tratamento e da disposição de seus gestores em fornecer o resíduo necessário para desenvolvimento da pesquisa. O sistema de tratamento de água residuária da empresa consistia em tanques ou câmaras de sedimentação, sendo que o primeiro deles era dividido em três zonas (Figura 2): (a) zona com predominância de concreto descartado (pasta de cimento e agregados miúdos e graúdos); (b) Zona de transição composta por maior parte de pasta de cimento e agregado miúdo e (c) Zona composta em grande parte por finos sedimentados em forma de placas. Dessa forma, foi possível a separação de um resíduo com menor granulometria, sendo esse coletado da zona (c).

O material coletado no tanque (Figura 1a) estava úmido e para que se pudesse ser utilizado houve a necessidade de uma secagem em estufa a $105^{\circ} \mathrm{C}$ (Figura 1b). A moagem se deu de forma manual com o auxílio de um almofariz e mão de gral e, em seguida, o material foi peneirado em uma peneira de abertura de 0,5 mm. O material passante era separado para uso e o retido era novamente moído para diminuir o tamanho dos grãos (Figura 1c).

O resíduo de borracha utilizado é aquele provindo da recauchutagem de pneu (Figura 1d). Uma vez que o estudo consistiu em empregar o granulado de borracha no lugar do agregado miúdo, fez-se uso do resíduo com granulometria semelhante a tal. Para tanto, o granulado foi coletado e posteriormente peneirado na peneira de abertura de 4,75 mm, pois, segundo a ABNT NBR 9935 [28], agregados miúdos são aqueles cujos grãos passam pela peneira com essa abertura. Por fim, os resíduos e o cimento foram separados em kits compostos pelos materiais que seriam utilizados para cada traço, facilitando a mistura deles no dia de moldagem conforme Figura 1e.

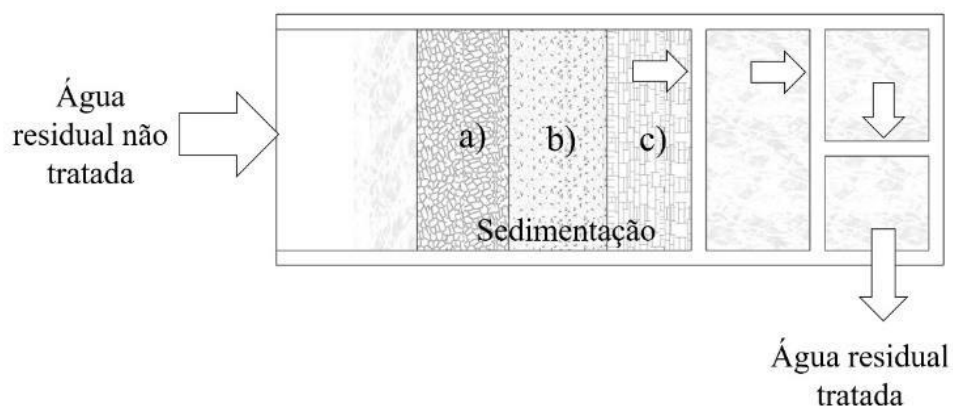

Figura 2: Zonas do tanque de sedimentação.

\subsection{Ensaios de caracterização química}

A caracterização química dos materiais foi dividida em duas etapas: a) análise da composição química elementar do cimento CP V-ARI, da LRC-S, do granulado de borracha e da areia artificial; e b) ensaio de difração de raios $\mathrm{X}$ da LRC-S.

A composição química elementar dos materiais foi determinada com o auxílio do espectrômetro de fluorescência de raios X por energia dispersiva (Schimadzu EDX 7000/8000). Antes do ensaio, as amostras avaliadas foram colocadas em estufas a $105^{\circ} \mathrm{C}$ por um período contínuo de $24 \mathrm{~h}$, e homogeneizadas a fim de minimizar possíveis alterações do resultado.

Já a LRC-S foi também caracterizada estruturalmente por difração de raios-X (DRX), e os difratogramas foram obtidos através de difratômetro XRD-6100 Shimadzu, utilizando a radiação CuK $\alpha$ do cobre ( $\lambda=$ $1,54148 \AA$ ), no intervalo angular na faixa $5^{\circ} \leq 2 \theta \leq 90^{\circ}$, e com passo para contagem de $0,01^{\circ}$. O difratograma obtido foi comparado com o banco de dados do ICDD - International Center for Diffraction Data, através dos Powder Diffraction File (PDF).

\subsection{Ensaios de caracterização física}

As curvas granulométricas da areia artificial, do granulado de borracha e da LRC-S foram designadas conforme o prescrito pela NBR NM 248 [29], utilizando as peneiras com as malhas descritas na Tabela 1. 
Tabela 1: Série de peneiras utilizadas no ensaio de granulometria.

\begin{tabular}{c|c|c|c|c|c|c|c|c|c|c|c|c}
\hline \multicolumn{10}{c}{} & \multicolumn{10}{c}{ Malhas } \\
\hline Abertura da malhas & $3 / 8$ & $1 / 4$ & 4 & 8 & 9 & 16 & 20 & 30 & 50 & 100 & 200 & 270 \\
\hline $\mathrm{mm}$ & 9,5 & 6,3 & 4,75 & 2,36 & 2,00 & 1,18 & 0,85 & 0,6 & 0,3 & 0,15 & 0,075 & 0,053 \\
\hline
\end{tabular}

O ensaio de densidade de partículas foi realizado com o cimento CP V-ARI, a areia artificial, a LRC-S e a borracha e os materiais foram avaliados conforme metodologia proposta pela EMBRAPA [30]. Entretanto, no caso dos resíduos foi necessária uma adaptação. Segundo o referido método, o ensaio deveria ser realizado com o auxílio de um balão volumétrico de $50 \mathrm{ml}$. No entanto, devido à baixa densidade da borracha e alto índice de finura de LRC-S, o volume era preenchido em quase sua totalidade e, assim, o álcool não conseguia umedecer toda sua massa. Portanto, para o caso dos resíduos, foi utilizado um balão volumétrico de $100 \mathrm{ml}$ para a mesma massa de material.

\subsection{Definição dos traços e das porcentagens de substituição}

Foi realizada uma parceria junto a uma empresa especializada na fabricação de peças pré-moldadas, a qual ficou responsável por fornecer materiais, mão-de-obra e maquinário para a confecção dos tijolos. O traço adotado como referência para todos os ensaios teve a relação $1 / 12$ de cimento/agregado, em massa, conforme utilizado por KOU, ZHAN e POON [20], e o microconcreto utilizado tinha consistência seca, com relação água/cimento de 1,2; apresentando um slump de aproximadamente $0 \mathrm{~mm}$. Os tijolos maciços de concreto tinham as seguintes dimensões: 200 × 100 × 60 mm, conforme Figura 3 .

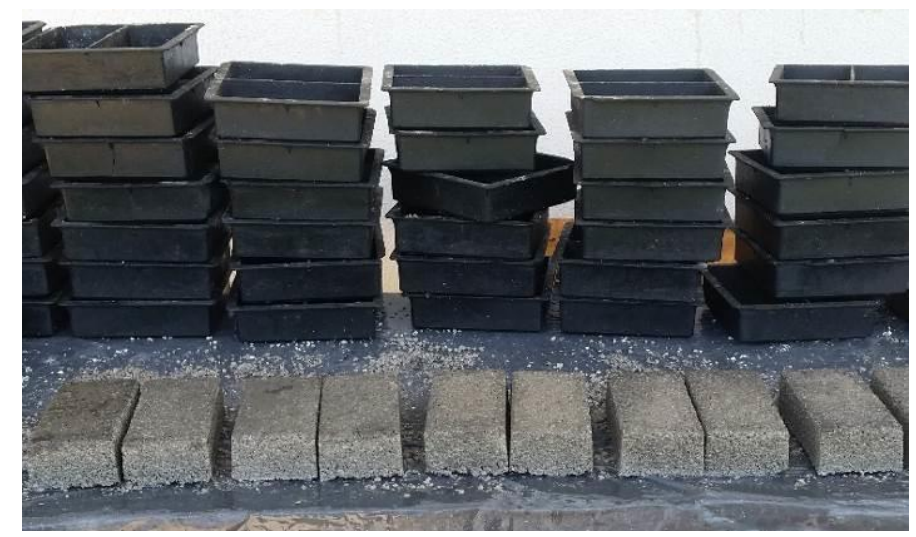

Figura 3: Tijolos de concreto após a desmoldagem.

Para determinação das faixas ótimas da associação dos resíduos de borracha e a LRC-S para produção de tijolos de concreto foi adotado o Delineamento Composto Central Rotacional (DCCR).

A matriz dos ensaios a serem realizados foi gerada utilizando os seguintes valores codificados dos níveis dos fatores: baixo (-1), alto $(+1)$, ponto central $(0)$ e pontos axiais $( \pm \alpha)$. Foi adotado $\alpha$ igual a 1,4142 , pois segundo DIAMOND [31], para esse valor, o planejamento apresenta propriedades de rotacionalidade e ortogonalidade, sendo que, pela rotacionalidade se obtém variâncias idênticas para pontos situados a mesma distância do centro, em qualquer direção e a ortogonalidade permite estimar independentemente os coeficientes do modelo [32].

O DCCR foi realizado com dois níveis originais, sendo $2^{\mathrm{K}}(\mathrm{K}=2$ fatores; 2 níveis $)$ pontos fatoriais, mais $2 \times \mathrm{K}$ pontos axiais e mais cinco repetições do ponto central, totalizando 13 ensaios ou corridas. Salienta-se que as repetições do ponto central possibilitam determinar o erro padrão do modelo [33]. O nível alto foi estipulado como sendo a maior porcentagem de substituição dos resíduos nos tijolos, e que garanta o atendimento as normas pertinentes. Para o ponto axial baixo determinou a ausência de resíduos.

Tem-se então como variáveis independentes as porcentagens de substituição do granulado de borracha $\left(\mathrm{X}_{1}\right)$ e da LRC-S $\left(\mathrm{X}_{2}\right)$. Como variável dependente tem-se a resistência à compressão $\left(\mathrm{Y}_{1}\right)$ e a absorção de água $\left(\mathrm{Y}_{2}\right)$, ambos aos 28 dias.

Através de cada resposta $Y_{i}$ foram representadas matematicamente o comportamento das variáveis dependentes, conforme a Equação 1. Vale destacar que, para se obter cada equação são correlacionados os coe- 
ficientes dos modelos de regressão e as variáveis independentes, sobre cada variável resposta.

$$
Y=\beta_{0}+\beta_{1} X_{1}+\beta_{2} X_{2}+\beta_{12} X_{1} X_{2}+\beta_{11} X_{1}^{2}+\beta_{22} X_{2}^{2}
$$

Sendo: Y: resposta predita; $\beta_{0}, \beta_{1}, \beta_{2}, \beta_{12}, \beta_{11}$ e $\beta_{22}$ são os parâmetros do modelo de regressão.

As superfícies de resposta, gráficos de Pareto e de contorno e os modelos de regressão das variáveis independentes foram gerados com o emprego do módulo DoE do aplicativo Statistica ${ }^{\circledR} 10.0$ [34]. A adequação dos modelos propostos foi avaliada pela proporção da variação explicada pelo modelo, isto é, pela análise do coeficiente de determinação $\left(\mathrm{R}^{2}\right)$ e pela análise de variância (ANOVA).

Partindo dos resultados obtidos com a análise estatística foram definidos quatro traços para validação dos teores de substituição: um de referência (sem adição de resíduos), e os demais com porcentagens de substituições que apresentaram resistência à compressão superior a $3 \mathrm{MPa}$, estabelecido pela ABNT NBR 6136 [24] para blocos de concreto da classe C. Salienta-se que foi adotado um traço com o máximo de porcentagem de substituição que atendeu a referida norma, um com o mínimo de resíduo e um intermediário.

\subsection{Proporcionamento e produção dos tijolos de concreto}

O proporcionamento dos materiais teve início no laboratório com a preparação dos kits de moldagem contendo as frações de cimento e de lama residual que foram utilizadas na confecção dos tijolos. Já as proporções de areia artificial e da água foram mensuradas diretamente na empresa de pré-moldados. Como a areia artificial disponível estava úmida, utilizou-se do ensaio expedito da frigideira para mensurar a umidade e reajustar o traço.

Para dar início à mistura dos materiais, a betoneira foi preparada para utilização, sendo lavada e imprimada antes de cada traço produzido. Após este processo, os materiais foram misturados por cerca de $2 \mathrm{~min}$ e, em seguida, colocados em fôrmas plásticas dispostas na mesa vibratória. O processo de compactação e adensamento foi realizado em uma mesa vibratória de dimensões de $2 \mathrm{~m} \times 1 \mathrm{~m}$, realizado em duas camadas para melhor adensamento, com duração aproximada de 1 minuto de vibração em cada camada. Posteriormente foi dado acabamento a face exposta dos blocos para garantir uniformidade.

Após a moldagem, os tijolos foram envoltos por uma lona e dispostos no pátio da empresa durante um dia, sendo molhados por duas vezes dentro deste período. No dia seguinte, os tijolos foram desmoldados e submetidos à cura úmida por imersão em água por 7 dias. Após esse período os tijolos foram secos ao ar conforme prescreve a ABNT NBR 12118 [35].

\subsection{Ensaio de compressão simples e absorção de água}

Os ensaios de compressão e absorção de água dos corpos de prova foram realizados segundo a NBR 12118 [35] e a NBR 8492 [36], respectivamente. A determinação da resistência à compressão foi auxiliada pela prensa hidráulica modelo YAW-2000 - Classe 1, calibrada de acordo com a NBR NM ISO 7500-1 [37]. Com o objetivo de acompanhar o desenvolvimento dos tijolos de concreto ao longo do período de cura, foram realizados os ensaios de resistência à compressão aos 3, 7, 14, 28 e 56 dias. Não foram realizados nenhum tratamento superficial, ou capeamento dos tijolos, tendo em vista a superfície uniforme adquirida neles durante a produção.

O tamanho da amostra para realizar os ensaios de compressão simples foi determinado de acordo com a NBR 6136 [24], que recomenda um mínimo de seis (6) tijolos para realização do ensaio, quando não se tem o desvio padrão da fábrica. Já o ensaio de absorção de água foi realizado apenas aos 28 dias, sendo utilizadas três unidades para cada traço.

Assim, para cada tijolo foi calculado o valor de absorção de água em porcentagem a partir da Equação $2[35]:$

$$
A=\frac{m_{2}-m_{1}}{m_{1}} \cdot 100
$$

Em que:

$A$ é a Absorção de cada corpo de prova, expressa em porcentagem (\%);

$m_{l}$ é a massa do corpo de prova seco, expressa em gramas (g);

$m_{2}$ é a massa do corpo de prova saturado, expressa em gramas (g). 


\subsection{Análise dos resultados}

Como a ideia deste estudo é propor um novo produto e que ainda não apresenta normatização específica, nesse contexto, a análise de viabilidade dos tijolos produzidos foi realizada de três maneiras:

- comparação com os limites de resistência à compressão mínimos, estabelecidos pela NBR 6136 [24] de $3 \mathrm{MPa}$ para tijolos de concreto da classe C, pela NBR 8491 [23] de 2 MPa para tijolos de solocimento e pela NBR 7170 [22] de 1,5MPa para tijolos maciços cerâmicos;

- $\quad$ verificação do limite máximo de absorção médio e individual de $10 \%$ e $12 \%$, respectivamente, de acordo com a NBR 6136 [24], e de $20 \%$ e 22\% de acordo com a NBR 8491 [23];

- análise estatística entre os dados através das superfícies de resposta, dos gráficos de Pareto e de contorno, dos modelos de regressão das variáveis e da Análise de Variância (ANOVA) com significância $\mathrm{p}=0,05$.

Ao final foi repetida a dosagem dos traços ótimos de modo a validar as porcentagens obtidas.

\section{RESULTADOS}

\subsection{Distribuição granulométrica e densidade de partículas dos materiais}

As curvas granulométricas dos resíduos e agregados utilizados na primeira parte do estudo estão apresentadas na Figura 4. Os materiais utilizados para validação dos resultados estão representados na Figura 5.

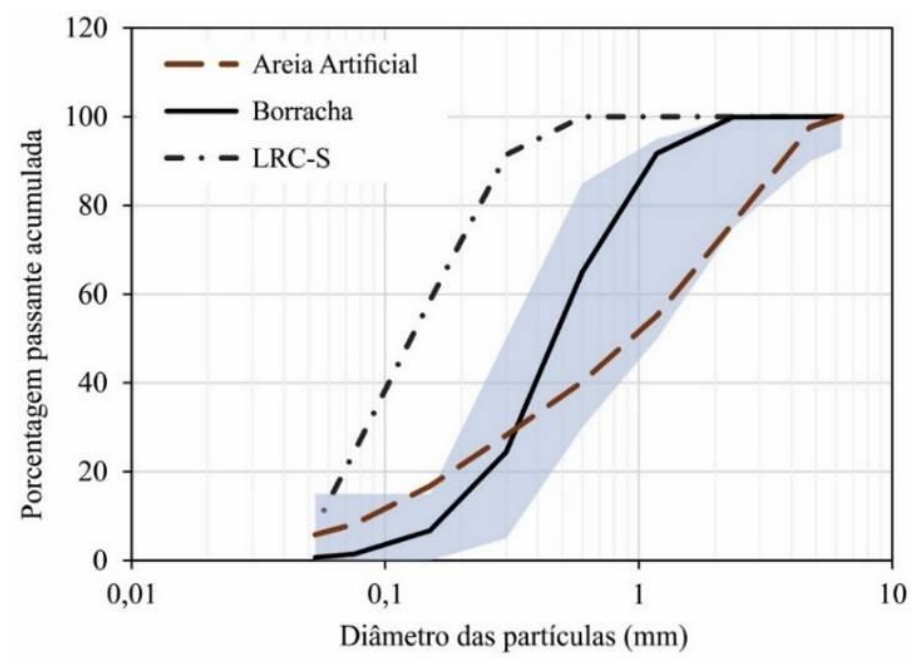

Zona utilizável para agregado miúdo (NBR 7211/2009)

Figura 4: Distribuição granulométrica da Lama Residual de Concreto Seca (LRC-S), da borracha e da areia artificial. 


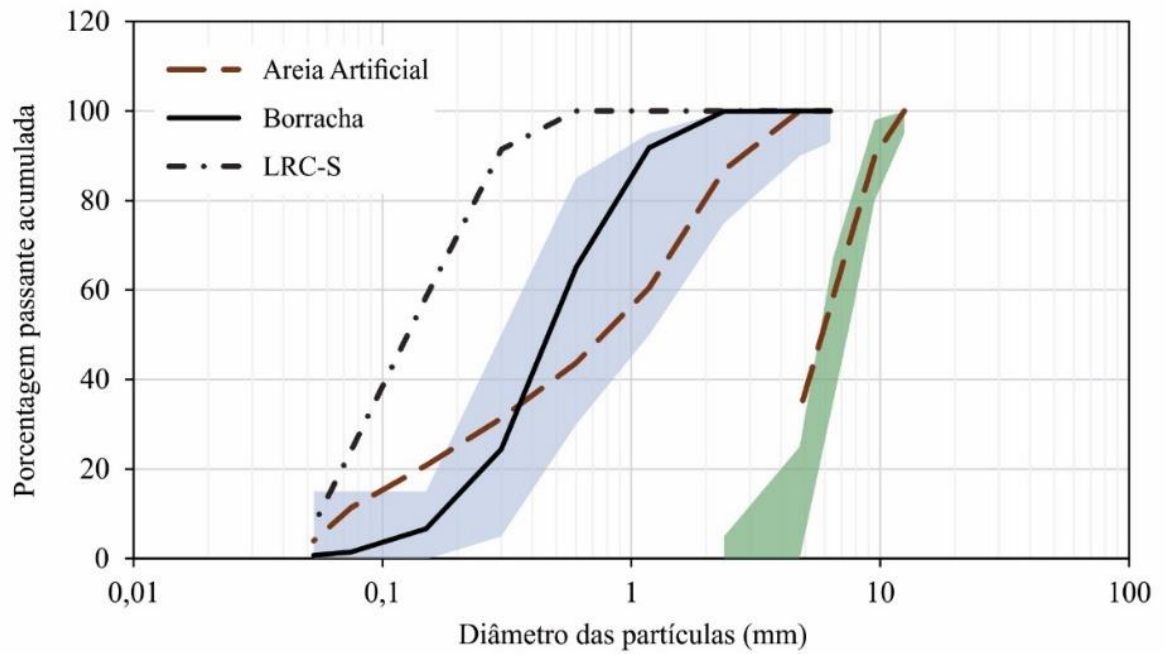

Zona utilizável para agregado miúdo (NBR 7211/2009)

Zona utilizável para agregado graúdo (NBR 7211/2009)

Figura 5: Distribuição granulométrica da Lama Residual de Concreto Seca (LRC-S), da borracha e da areia artificial para a validação do estudo experimental.

No caso da borracha, a maior parcela da massa total ficou retida nas peneiras com abertura de $300 \mu \mathrm{m}$ e $600 \mu \mathrm{m}$. Já a maior parte da areia ficou armazenada nas duas peneiras anteriores, de 2,36 e 1,18 $\mathrm{mm}$. Percebe-se que a borracha apresenta uma distribuição mais variada e com partículas menores se comparada a areia, porém ainda se encontra na zona utilizável para agregado miúdo da ABNT NBR 7211 [38]. Essa granulometria mais fina da borracha pode auxiliar na resistência, pois, segundo SADEK e EL-ATTAR [39] os tijolos com borracha mais fina apresentaram maior resistência se comparados com os confeccionados com borracha grossa. Já a LRC-S apresentou diâmetros dos grãos bem menores, sendo que a peneira de abertura de $75 \mu \mathrm{m}$ foi a responsável por reter a maior parcela da massa. Tem-se assim, que materiais finamente moídos podem se comportar como filer, preenchendo os vazios entre os materiais e trazendo benefícios para o concreto [27].

Com relação a areia artificial disponível para a moldagem de cada estudo, pode-se perceber que, no estudo inicial, ela se enquadrava apenas como agregado miúdo, e já no estudo de validação ela pode ser considerada como agregado total, ou seja, possuía uma distribuição granulométrica constituída por agregados graúdos e miúdos. Em ambos os casos atendem a ABNT NBR 6136 [24] com relação aos materiais utilizados, bem como as zonas de utilização para agregados da ABNT NBR 7211 [38].

Já avaliando a densidade de partículas, foi observado que, dentre os materiais constituintes, a borracha possui a menor densidade $\left(1,17 \mathrm{~g} / \mathrm{cm}^{3}\right)$, seguida pela LRC-S $\left(2,19 \mathrm{~g} / \mathrm{cm}^{3}\right)$, areia artificial $\left(2,52 \mathrm{~g} / \mathrm{cm}^{3}\right)$ e pelo cimento $\left(2,84 \mathrm{~g} / \mathrm{cm}^{3}\right)$. Tem-se, então, que a densidade das partículas do cimento foi $30 \%$ superior à densidade encontrada para a LRC-S, e a densidade da borracha é duas vezes menor em relação ao valor encontrado para areia artificial. Assim, ambos os resíduos possuem densidades menores do que os materiais a serem substituídos, o que leva à uma redução da densidade final dos tijolos.

\subsection{Ensaio de EDX e Difratograma de Raios-X}

As caracterizações químicas elementares da borracha, do cimento CP V-ARI, da areia artificial e da LRC$\mathrm{S}$ foram determinadas através do ensaio de EDX (Tabela 2).

Tabela 2: Caracterização química das parcelas elementares dos materiais utilizados.

\begin{tabular}{c|c|c|c|c}
\hline ELEMENTO & $\begin{array}{c}\text { BORRACHA } \\
(\boldsymbol{\%})\end{array}$ & $\begin{array}{c}\text { CP V - ARI } \\
(\boldsymbol{\%})\end{array}$ & $\begin{array}{c}\text { AREIA ARTIFICIAL } \\
(\boldsymbol{\%})\end{array}$ & $\begin{array}{c}\text { LRC-S } \\
(\boldsymbol{\%})\end{array}$ \\
\hline $\mathbf{C a}$ & 1,41 & 82,32 & 3,88 & 63,5 \\
\hline $\mathbf{S i}$ & 12,82 & 8,41 & 62,74 & 20,29 \\
\hline $\mathbf{F e}$ & 1,35 & 4,87 & 4,34 & 8,31 \\
\hline $\mathbf{A l}$ & 0,00 & 0 & 11,67 & 2,85 \\
\hline
\end{tabular}




\begin{tabular}{c|c|c|c|c}
\hline $\mathbf{K}$ & 1,23 & 0,6 & 15,91 & 2,52 \\
\hline $\mathbf{S}$ & 16,01 & 2,27 & 0,06 & 0,89 \\
\hline $\mathbf{T i}$ & 0,19 & 0,43 & 0,51 & 0,8 \\
\hline $\mathbf{S r}$ & 0 & 0,77 & 0,05 & 0,37 \\
\hline $\mathbf{M n}$ & 0 & 0,13 & 0,12 & 0,2 \\
\hline $\mathbf{Z n}$ & 66,85 & 0,08 & 0,03 & 0,07 \\
\hline $\mathbf{C u}$ & 0,16 & 0,04 & 0,05 & 0,04 \\
\hline $\mathbf{R b}$ & 0 & 0 & 0,26 & 0,04 \\
\hline $\mathbf{C r}$ & 0 & 0,05 & 0,02 & 0,04 \\
\hline $\mathbf{V}$ & 0 & 0,02 & 0 & 0,03 \\
\hline $\mathbf{Z r}$ & 0 & 0 & 0,05 & 0,03 \\
\hline $\mathbf{N b}$ & 0 & 0 & 0,01 & 0,01 \\
\hline $\mathbf{P}$ & 0 & 0 & 0,24 & 0 \\
\hline $\mathbf{I r}$ & 0 & 0 & 0,04 & 0 \\
\hline $\mathbf{P b}$ & 0 & 0 & 0,02 & 0 \\
\hline $\mathbf{N i}$ & 0 & 0,01 & 0 & 0 \\
\hline
\end{tabular}

Sabe-se que durante a fabricação dos pneus há a utilização de zinco $(Z n)$ e enxofre $(S)$ como ativador e agente de vulcanização, o que explica a maior concentração desses elementos no resíduo de borracha [2]. Analisando a composição química da borracha e do agregado miúdo, percebe-se que não há semelhanças significativas que justifique quimicamente a substituição da areia por esse resíduo, a não ser o preenchimento físico da pasta.

Para o cimento CP V-ARI, a maior concentração foi de cálcio $(\mathrm{Ca})$, presente nos compostos de óxidos e carbonatos de cálcio responsáveis pela formação dos cristais de $C_{3} S$, por exemplo, durante o processo de hidratação do cimento. Foi possível perceber também altas concentrações de cálcio $(\mathrm{Ca})$ e silício $(\mathrm{Si})$ na LRC-S. Como esse resíduo é um subproduto de concreto original, justifica-se a presença desses componentes, pois estão fortemente presentes no cimento e na areia, produtos utilizados na fabricação do concreto.

Para conhecer melhor as características químicas da LRC-S, foi realizado o Difratograma de Raios-X (DRX) (Figura 6). Através do DRX foi confirmada a presença do Quartzo $\left(\mathrm{SiO}_{2}\right)$, da Portlandita $\left(\mathrm{Ca}(\mathrm{OH})_{2}\right)$, da Ilita $\left(\mathrm{Al}_{3} \mathrm{H}_{4} \mathrm{KO}_{13} \mathrm{Si}_{3}\right)$, do Aluminato tricálcico $\left(3 \mathrm{CaO} .(\mathrm{Al}, \mathrm{Fe})_{2} \mathrm{O}_{3} \cdot \mathrm{CaSO}_{4} \cdot n \mathrm{H}_{2} \mathrm{O}\right)$, da Celita $\left(3 \mathrm{CaO} \cdot \mathrm{Al}_{2} \mathrm{O}_{3}\right)$, que também é um Aluminato tricálcico, conhecida por $\mathrm{C}_{3} \mathrm{~A}$, dos Silicatos bicálcicos $\left(2 \mathrm{CaOSiO}_{2}\right.$ ou $\left.\mathrm{C}_{2} \mathrm{~S}\right)$ e tricálcicos $\left(3 \mathrm{CaOSiO}_{2}\right.$ ou $\left.\mathrm{C}_{3} \mathrm{~S}\right)$ e a presença do "Tetracalcium dialuminium dodecahydroxide carbonate pentahydrate" $\left(\mathrm{Al}_{2} \mathrm{Ca}_{4} \mathrm{H}_{22} \mathrm{O}_{20}\right)$.

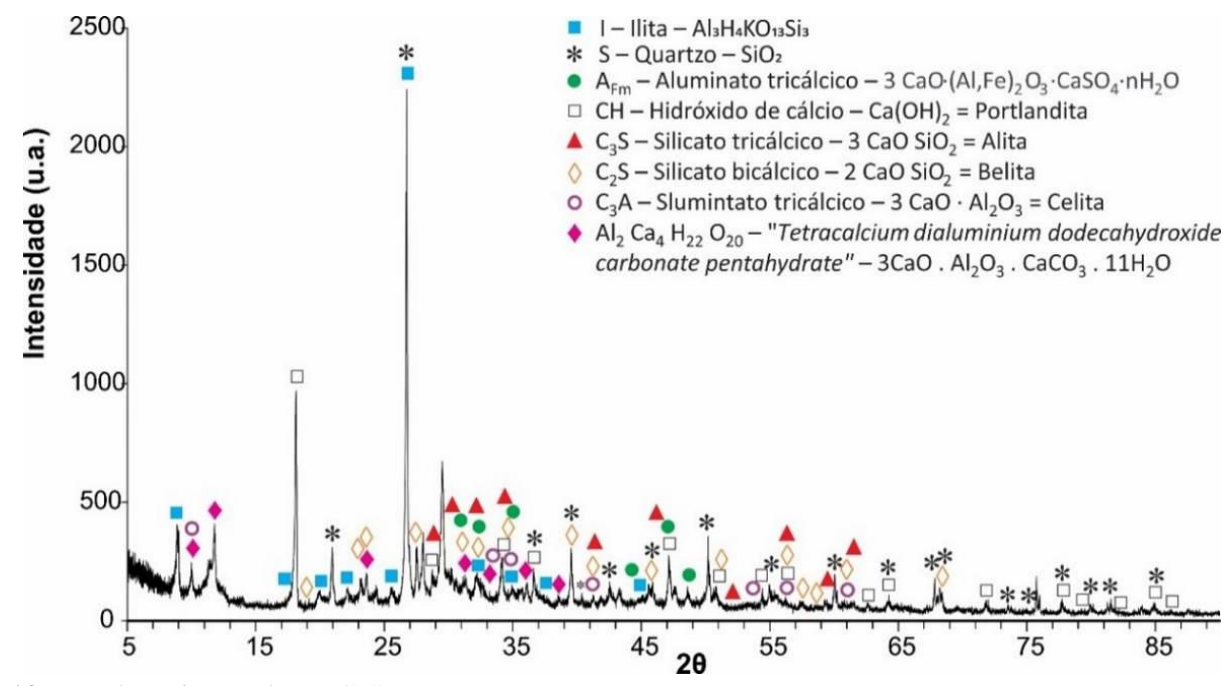

Figura 6: Difração de Raios-X da LRC-S. 
Resultados semelhantes foram encontrados por AUDO, MAHIEUX e TURCRY [19]. Em seu estudo apresentaram o Difratograma de Raios-X (DRX) referente a parcela menor e maior que $100 \mu \mathrm{m}$ da lama residual de concreto de quatro usinas de concreto distintas. Ressaltaram que a parcela mais grossa é formada basicamente por agregados, sendo observados a presença de Quartzo $\left(\mathrm{SiO}_{2}\right)$ e Calcita $\left(\mathrm{CaCO}_{3}\right)$, bem como agregados formados por Portlandita $\left(\mathrm{Ca}(\mathrm{OH})_{2}\right)$ e/ou CSH conglomerado. Na parcela mais fina também identificaram Quartzo, Calcita, Portlandita, Gesso $\left(\mathrm{CaSO}_{4} 2 \mathrm{H}_{2} \mathrm{O}\right)$ e silicatos de cálcio hidratados e anidros. Os autores salientaram, então, que a presença de silicatos de cálcio anidro demonstra um potencial residual de atividade hidráulica.

\subsection{Otimização das porcentagens de substituição para produção de tijolos de concreto com resíduos}

A partir dos ensaios de resistência à compressão dos estudos de SILVA et al. [25] e BONFIM et al. [26], foram definidos como nível alto do delineamento $20 \%$ de substituição tanto para a borracha quanto para a LRC-S. Vale ressaltar que a borracha será utilizada em substituição parcial do agregado miúdo e a LRC-S em substituição parcial ao cimento. Para tanto, foram adotadas como variáveis dependentes a resistência à compressão $\left(\mathrm{Y}_{1}\right)$ e a absorção de água $\left(\mathrm{Y}_{2}\right)$, ambos aos 28 dias. Os valores das variáveis independentes e seus respectivos níveis estão apresentados na Tabela 3, gerando a matriz de ensaios conforme Tabela 4. Salientase que a matriz de ensaios foi gerada pelos pontos fatoriais (T1 a T4), pontos axiais (T5 a T8) e mais cinco repetições do ponto central (T9 a T13), totalizando os 13 ensaios ou corridas.

Tabela 3: Variáveis independentes e respectivos níveis.

\begin{tabular}{ccccccc}
\hline \multirow{2}{*}{ Variáveis independentes } & \multicolumn{5}{c}{ Níveis considerados de substituição (\%) } \\
\cline { 3 - 7 } & & $\mathbf{- \alpha}$ & $\mathbf{- 1}$ & $\mathbf{0}$ & $\mathbf{1}$ & $+\boldsymbol{\alpha}$ \\
\hline $\mathbf{X}_{\mathbf{1}}$ & Borracha & 0,0 & 3,4 & 11,7 & 20,0 & 23,5 \\
\hline $\mathbf{X}_{\mathbf{2}}$ & LCR-S & 0,0 & 3,4 & 11,7 & 20,0 & 23,5 \\
\hline
\end{tabular}

Tabela 4: Matriz de ensaios.

\begin{tabular}{cccccc}
\hline Ensaio & $\mathbf{X}_{\mathbf{1}}$ & $\mathbf{X}_{\mathbf{2}}$ & Borracha $(\boldsymbol{\%})$ & LRC-S $(\boldsymbol{\%})$ & Traço \\
\hline $\mathbf{1}$ & -1 & -1 & 3,4 & 3,4 & $\mathrm{~T} 1$ \\
\hline $\mathbf{2}$ & 1 & -1 & 20 & 3,4 & $\mathrm{~T} 2$ \\
\hline $\mathbf{3}$ & -1 & 1 & 3,4 & 20 & $\mathrm{~T} 3$ \\
\hline $\mathbf{4}$ & 1 & 1 & 20 & 20 & $\mathrm{~T} 4$ \\
\hline $\mathbf{5}$ & $-\alpha$ & 0 & 0 & 11,7 & $\mathrm{~T} 5$ \\
\hline $\mathbf{6}$ & $+\alpha$ & 0 & 23,5 & 11,7 & $\mathrm{~T} 6$ \\
\hline $\mathbf{7}$ & 0 & $-\alpha$ & 11,7 & 0 & $\mathrm{~T} 7$ \\
\hline $\mathbf{8}$ & 0 & $+\alpha$ & 11,7 & 23,5 & $\mathrm{~T} 8$ \\
\hline $\mathbf{9}$ & 0 & 0 & 11,7 & 11,7 & $\mathrm{~T} 9$ \\
\hline $\mathbf{1 0}$ & 0 & 0 & 11,7 & 11,7 & $\mathrm{~T} 10$ \\
\hline $\mathbf{1 1}$ & 0 & 0 & 11,7 & 11,7 & $\mathrm{~T} 11$ \\
\hline $\mathbf{1 2}$ & 0 & 0 & 11,7 & 11,7 & $\mathrm{~T} 12$ \\
\hline $\mathbf{1 3}$ & 0 & 0 & 11,7 & 11,7 & $\mathrm{~T} 13$ \\
\hline
\end{tabular}

Partindo da matriz de ensaios e do traço base 1/12 de cimento/agregado, foi possível determinar a quantidade de cada material, de acordo com a Tabela 5. Salienta-se que a relação a/c utilizada foi de $1,2 \mathrm{e}$ que a massa de areia apresentada estava no estado seco. 
Tabela 5: Traço dos materiais.

\begin{tabular}{ccccc}
\hline Traço & Cimento $(\mathbf{k g})$ & LRC-S $(\mathbf{k g})$ & Areia $(\mathbf{k g})$ & Borracha $(\mathbf{k g})$ \\
\hline TR & 1 & 0 & 12 & 0 \\
\hline T1 & 0,97 & 0,03 & 11,81 & 0,19 \\
\hline T2 & 0,97 & 0,03 & 10,89 & 1,11 \\
T3 & 0,80 & 0,20 & 11,81 & 0,19 \\
\hline T4 & 0,80 & 0,20 & 10,89 & 1,11 \\
\hline T5 & 0,88 & 0,12 & 12 & 0 \\
\hline T6 & 0,88 & 0,12 & 10,69 & 1,31 \\
\hline T7 & 1 & 0 & 11,35 & 0,65 \\
\hline T8 & 0,77 & 0,24 & 11,35 & 0,65 \\
\hline T9 & 0,88 & 0,12 & 11,35 & 0,65 \\
\hline T10 & 0,88 & 0,12 & 11,35 & 0,65 \\
\hline T11 & 0,88 & 0,12 & 11,35 & 0,65 \\
\hline T12 & 0,88 & 0,12 & 11,35 & 0,65 \\
\hline T13 & 0,88 & 0,12 & 11,35 & 0,65 \\
\hline
\end{tabular}

Estão apresentados na Tabela 6 os valores (respostas) dos parâmetros de resistência à compressão simples, bem como da absorção de água dos tijolos referentes aos traços da Tabela 4, juntamente com o traço de referência TR.

Tabela 6: Resultados dos ensaios de resistência à compressão simples e absorção de água.

\begin{tabular}{ccc}
\hline Traço & $\begin{array}{c}\text { Resistência à com- } \\
\text { pressão }\left(\mathbf{Y}_{\mathbf{1}}\right)\end{array}$ & $\begin{array}{c}\text { Absorção } \\
\left(\mathbf{Y}_{\mathbf{2}}\right)\end{array}$ \\
\cline { 2 - 3 } $\mathbf{( \mathbf { M a } )}$ & $\mathbf{( \% )}$ \\
\hline TR & 5,53 & 14,41 \\
\hline T1 & 4,15 & 14,60 \\
\hline T2 & 0,70 & 21,28 \\
\hline T3 & 3,02 & 14,28 \\
\hline T4 & 1,12 & 22,91 \\
\hline T5 & 6,27 & 12,03 \\
\hline T6 & 0,44 & 23,86 \\
\hline T7 & 1,75 & 18,18 \\
\hline T8 & 1,62 & 19,29 \\
\hline T9 & 1,97 & 18,53 \\
\hline T10 & 1,26 & 20,82 \\
\hline T11 & 1,03 & 19,49 \\
\hline T12 & 1,44 & 21,54 \\
\hline T13 & 0,78 & 22,12 \\
\hline
\end{tabular}

Para as respostas das variáveis dependentes são expressos os coeficientes de regressão polinomial de segunda ordem, estatisticamente significativas em um nível de $95 \%$ de confiança, conforme Tabela 7. São apresentados também os coeficientes de determinação $R^{2}$ e $R_{a j}^{2}$, que fornecem "uma medida da proporção de variação explicada pela equação de regressão em relação à variação total das respostas" [33]. Vale destacar os valores encontrados para os coeficientes de determinação $R^{2}$ e $R_{a j}^{2}$, que, para todos os parâmetros, ficaram acima de $93 \%$ e $88 \%$, respectivamente, indicando um excelente ajuste do modelo. 
Tabela 7: Regressões polinomiais de segunda ordem das variáveis dependentes utilizadas na geração das Superfícies de Resposta, gráficos de Pareto e de contorno, com seus respectivos coeficientes de determinação.

\begin{tabular}{|c|c|c|}
\hline Modelos & $\mathrm{R}^{2}(\%)$ & $\mathrm{R}^{2}$ aj. $(\%)$ \\
\hline$Y_{1}=6,787767-0,597658 X_{1}+0,013972 X_{1}^{2}$ & 93,58 & 88,99 \\
\hline$Y_{2}=10,93665+0,84167 X_{1}-0,01885 X_{1}^{2}$ & 94,18 & 90,03 \\
\hline
\end{tabular}

Estão apresentados nas Figuras 7 e 8 os gráficos de Pareto do delineamento experimental, com a indicação das variáveis significativas $(\mathrm{p}<0,05)$, em que se verificou que apenas os efeitos lineares $(\mathrm{L})$ e quadrático $(\mathrm{Q})$ da borracha foram considerados significativos para alteração da resistência à compressão, bem como da absorção de água. Os valores ao lado das barras são referentes aos valores da estatística do teste t, sendo o tamanho da barra proporcional ao efeito causado pela variável em questão sobre a variável resposta. Assim, percebe-se que os efeitos lineares da borracha provocam a redução da resistência à compressão, observado pelo sinal negativo do teste $\mathrm{t}$ (Figura 7) e o aumento da absorção, pelo sinal positivo (Figura 8).

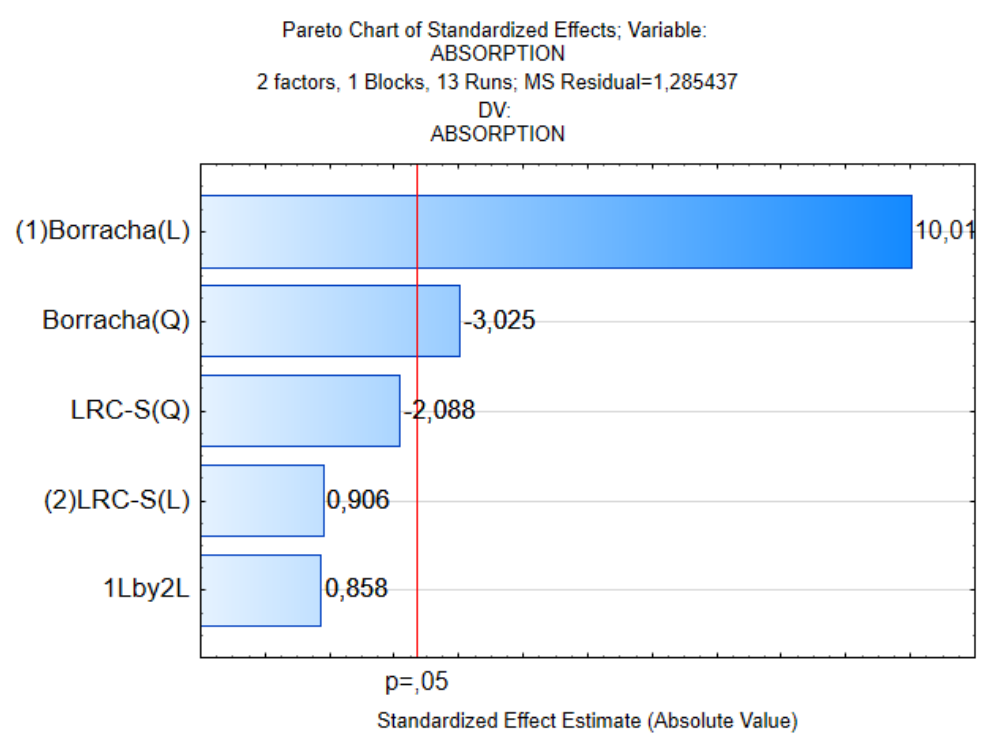

Figura 7: Gráfico de Pareto para análise da resistência à compressão por meio do DCCR, para os tijolos com adição de resíduos.

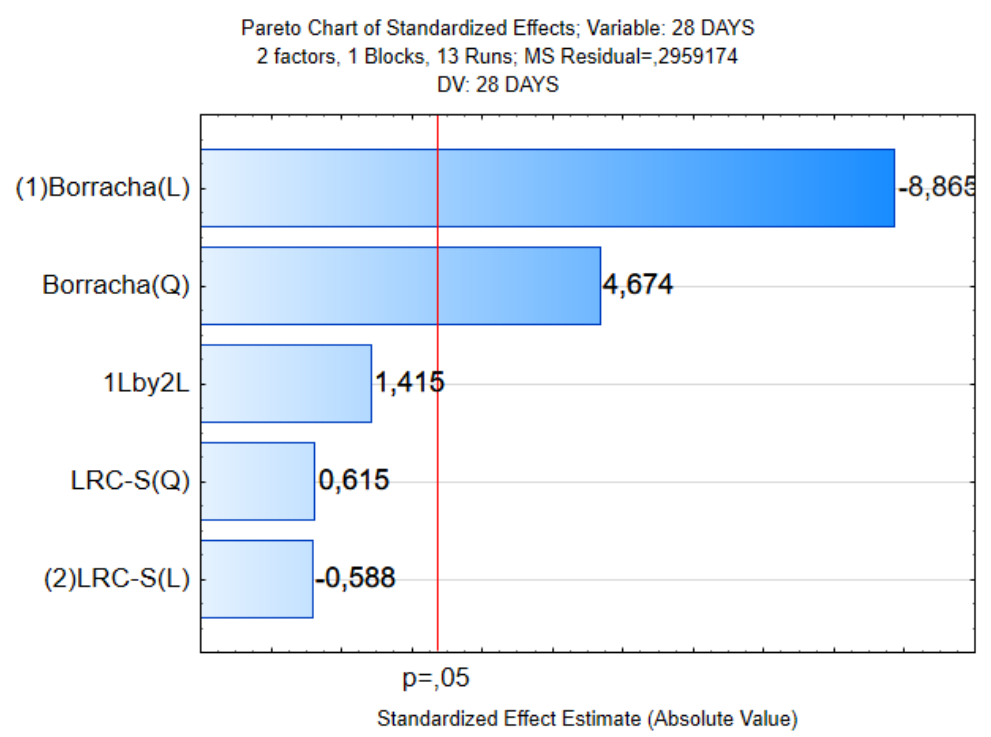

Figura 8: Gráfico de Pareto para análise da absorção de água por meio do DCCR, para os tijolos com adição de resíduos. 
Na Tabela 8 está apresentada a análise de variância (ANOVA) para resistência à compressão $\left(Y_{1}\right)$ e absorção de água $\left(Y_{2}\right)$, sendo os modelos de regressão, em todas as análises, significativas para p $<0,05$ e podem ser considerados preditivos. Com relação à falta de ajuste tem-se que, tanto para $Y_{1}$ quanto para $Y_{2}$, foi não significativa, revelando que os modelos referentes podem ser considerados válidos para fins preditivos.

Tabela 8: Análise de variância (ANOVA).

\begin{tabular}{c|c|c|c|c|c}
\hline \multicolumn{7}{c}{ Resistência à compressão $\left(\mathbf{Y}_{\mathbf{1}}\right)$ - 28 Dias } \\
\hline Fonte de Variação & G.L. & Soma dos quadrados & Quadrado médio & F calculado & p \\
\hline Regressão & 5 & 30,2084 & 6,0417 & 20,4168 & $0,0005^{*}$ \\
\hline Resíduo & 7 & 2,0714 & 0,2959 & & \\
\hline Falta de ajuste & 3 & 1,2522 & 0,4174 & 2,0381 & $0,2511^{\text {n.s. }}$ \\
\hline Erro puro & 4 & 0,8192 & 0,2048 & & \\
\hline Total & 12 & 32,2798 & & & \\
\hline
\end{tabular}

\begin{tabular}{c|c|c|c|c|c}
\hline \multicolumn{7}{c}{ Absorção de água $\left(\mathbf{Y}_{\mathbf{2}}\right) \mathbf{2} 28$ dias } \\
\hline Fonte de Variação & G.L. & Soma dos quadrados & Quadrado médio & F calculado & $\mathbf{p}$ \\
\hline Regressão & 5 & 145,6791 & 29,1358 & 22,6661 & $0,0003^{*}$ \\
\hline Resíduo & 7 & 8,9981 & 1,2854 & & \\
\hline Falta de ajuste & 3 & 0,2905 & 0,0968 & 0,0445 & $0,9858^{\text {n.s. }}$ \\
\hline Erro puro & 4 & 8,7075 & 2,1769 & & \\
\hline Total & 12 & 154,6771 & & & \\
\hline
\end{tabular}

*Valores significativos a 5\% de probabilidade.

n.s. Não Significativo

É apresentado na Figura 9 o gráfico de contorno e a superfície de resposta para a resistência à compressão quando considerada a interação das variáveis independentes que tiveram efeitos significativos. Verifica-se que conforme se aumenta as porcentagens dos resíduos se reduz a resistência à compressão.
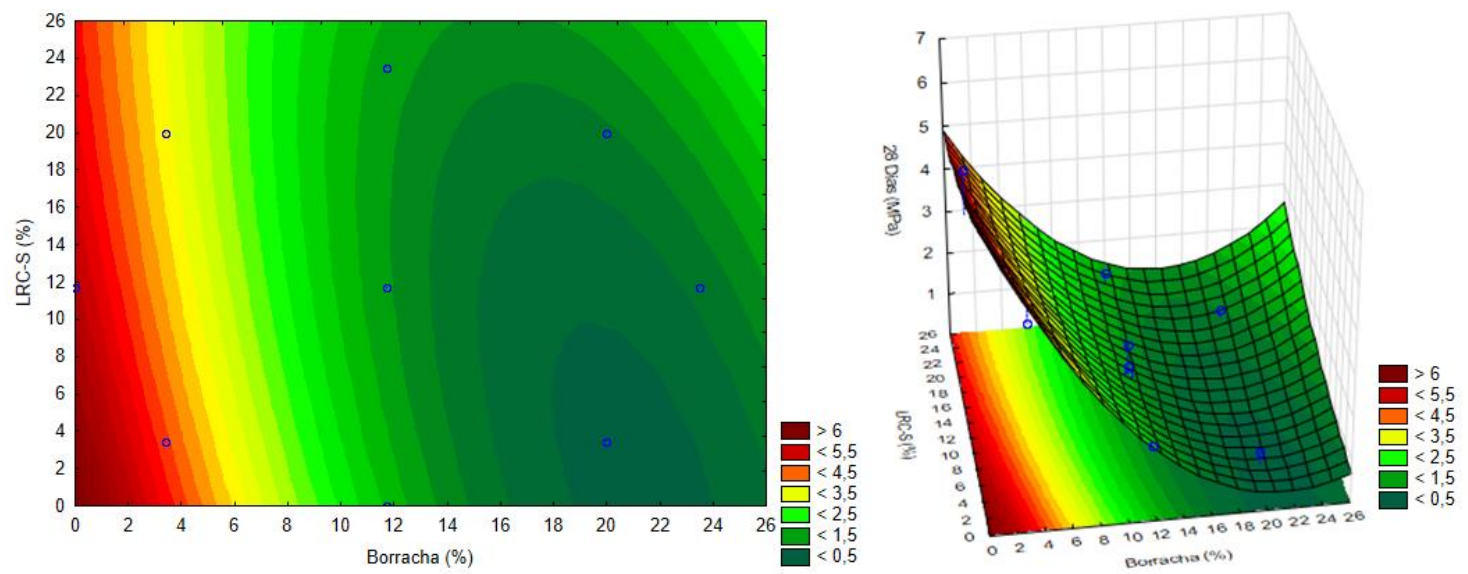

Figura 9: Superfície de contorno para a variação da resistência à compressão aos 28 dias em função das variáveis independentes.

Percebe-se, também pela Figura 9, que a LRC-S tem pouca influência na perda da resistência se comparada com a borracha. Observando as faixas de resistências, nota-se que as zonas vermelhas são as que apresentam as maiores resistências, no entanto, as zonas entre as cores amarela e vermelha indicam resistências superiores a $3 \mathrm{MPa}$, atendendo as normas NBR 7170 [22], NBR 8491 [23] e NBR 6136 [24]. Tem-se, então, que o limite máximo de substituição do agregado por borracha é de cerca de $8 \%$ com aproximadamente $15 \%$ de LRC-S, em substituição ao cimento.

Analisando apenas as médias da resistência à compressão dos tijolos aos 28 dias, conforme Figura 10 foi possível notar a diminuição de resistência dos tijolos com a adição da borracha. O traço T7, por exemplo, 
que possuía apenas substituição da areia por borracha, sofreu uma queda na sua resistência de $68 \%$ em relação ao traço de referência. Pode-se destacar também o traço T6, que possuía a maior porcentagem de borracha, $23,5 \%$, e que teve uma redução de $92 \%$ se comparado ao tijolo sem adição de resíduo.

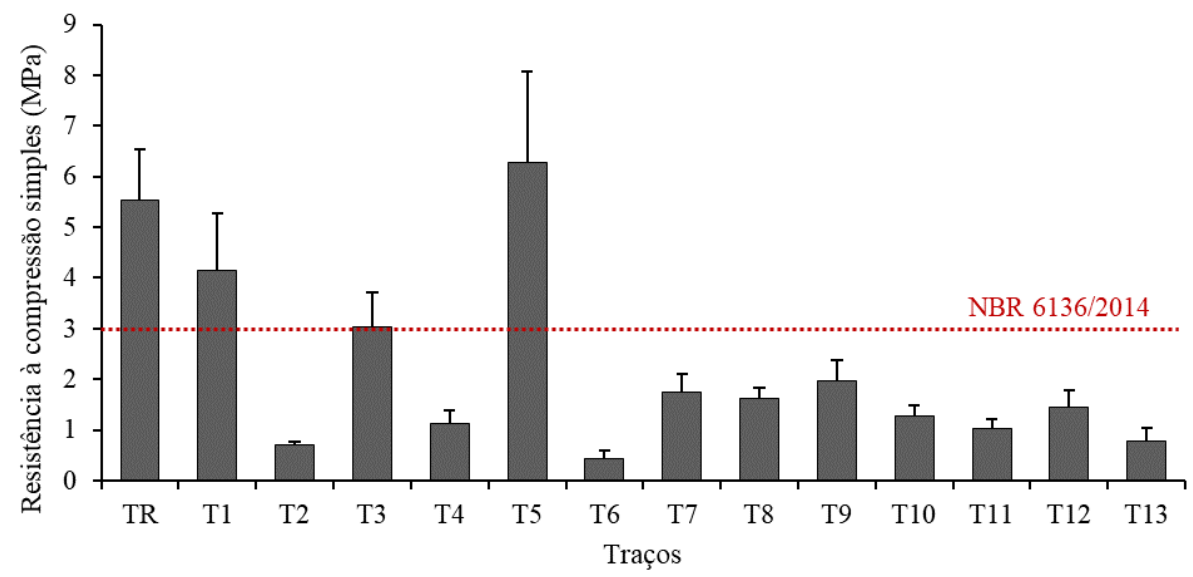

Figura 10: Resistência à compressão dos tijolos aos 28 dias.

Esse fenômeno já foi observado em outros trabalhos. SILVEIRA et al. [40] verificou uma redução de até $44 \%$ na resistência de corpos de prova com substituição de $10 \%$ da areia por borracha, sendo que foi constatado que seria necessário um acréscimo expressivo de cimento (cerca de 30\%) para atingir os mesmos resultados que o concreto sem essa mudança.

Entretanto, a adição de LRC-S provoca o efeito inverso. No traço T5, com substituição apenas do cimento, observou-se um acréscimo de $13 \%$ da resistência à compressão. KOU, ZHAN e POON [20] atribuem esse ganho de resistência à presença de silicatos não hidratado na LRC-S, conforme observado no ensaio de DRX, e no efeito filer que esse material pode causar na mistura.

Contudo, AUDO, MAHIEUX e TURCRY [19] verificaram que o aumento de resistência pode ser limitado pelo teor da substituição, sendo que a melhora nos resultados ocorre com uma pequena adição do resíduo. A partir de uma determinada quantidade, as propriedades mecânicas do concreto passam a ser comprometidas. Dessa forma, a mistura de borracha e LRC-S pode balancear os efeitos desses materiais a fim de se obter a resistência mínima desejada de $3 \mathrm{MPa}$, desde que essa combinação seja feita em proporções adequadas.

Avaliando os resultados médios de resistência à compressão simples ao longo das idades, conforme Figura 11, pode-se perceber que os traços mantiveram um comportamento semelhante, tendo um acréscimo gradual ao longo dos dias. É notório que aos 3 dias os tijolos já apresentavam grande ganho de resistência, podendo ser explicado pelo uso do cimento CP V-ARI, cuja característica marcante é adquirir grande parte de sua resistência já nas primeiras idades. Um ponto a ser observado é a perda de resistência aos 56 dias dos traços com adição de borracha, fato ainda não estudado pela literatura, sendo necessário, então, para trabalhos futuros, outras análises para verificar o comportamento dos tijolos com borracha em idades avançadas. 


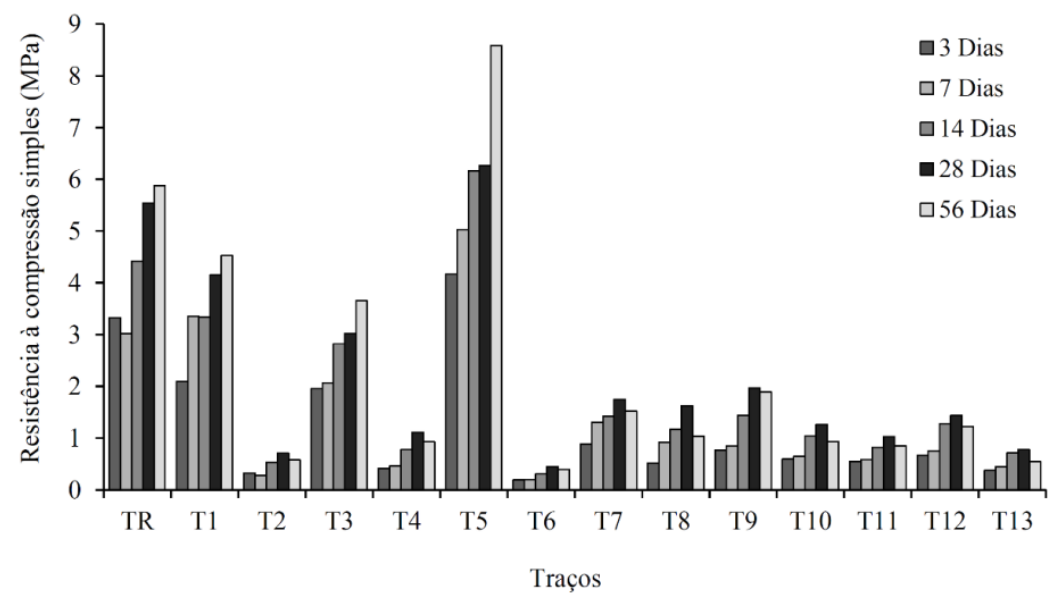

Figura 11: Resistência à compressão dos tijolos aos 3, 7, 14, 28 e 56 dias.

A superfície de contorno para a absorção de água quando considerada a interação das variáveis independentes que tiveram efeito significativo é apresentada na Figura 12. Verifica-se que conforme se aumenta as porcentagens dos resíduos se aumenta a absorção de água. Percebe-se, também que a LRC-S tem pouca influência no aumento da absorção de água se comparada com a borracha. Observando as faixas de absorção, nota-se que as zonas verdes são as que apresentam menores valores, sendo que apenas a zona verde-escura, com absorção menor que 10\%, atende a ABNT NBR 6136 [24]. No entanto as zonas de verde até vermelho claro, com absorção menor que 20\%, atendem a ABNT NBR 8491[23].
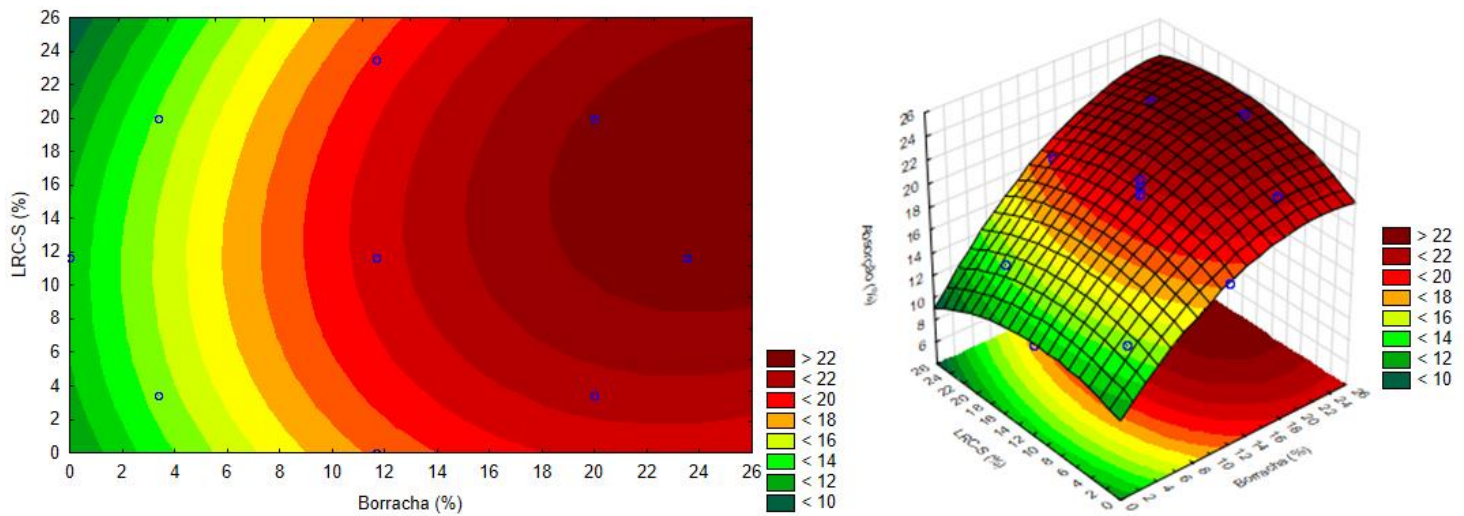

Figura 12: Superfície de contorno para a variação da absorção de água aos 28 dias em função das variáveis independentes.

Analisando os dados médios de absorção de água aos 28 dias, conforme Figura 13, percebe-se que a maioria dos traços obteve uma maior porcentagem de absorção quando comparado ao de referência (TR). O aumento na absorção ocorreu devido a utilização da borracha. Esse material tem uma fraca ligação com o cimento, favorecendo a presença de vazios na mistura e, consequentemente, aumentando a absorção de água [41]. 


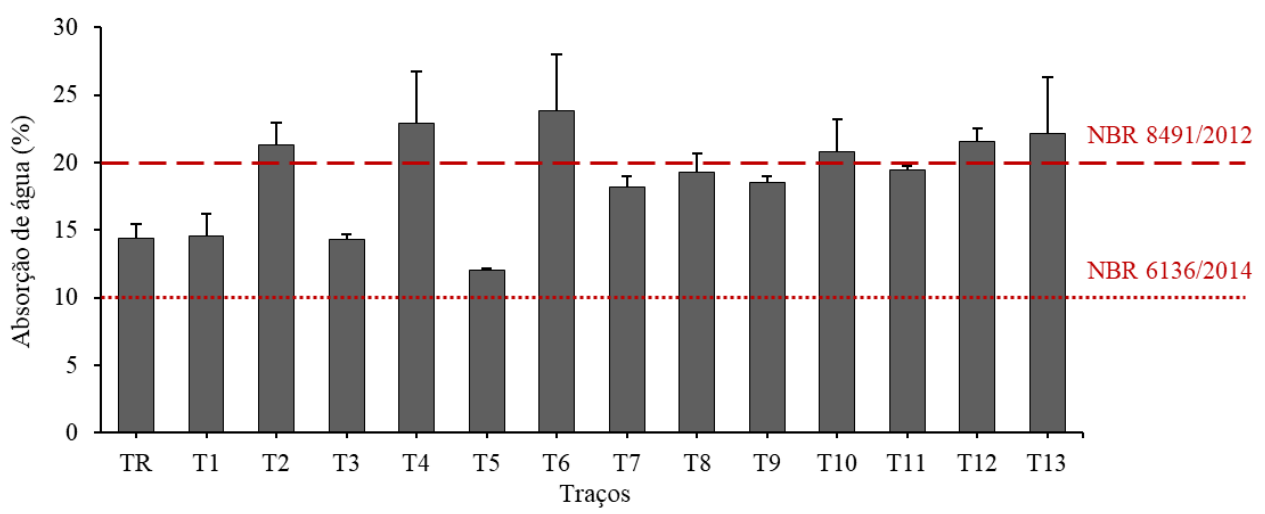

Figura 13: Absorção de água dos tijolos de concreto.

A influência da adição da LRC-S, em determinadas porcentagens pode acarretar o aumento ou a diminuição da absorção. KOU, ZHAN e POON [20] concluíram que o uso desse material, em grandes porcentagens, pode aumentar a absorção devido à baixa formação de cristais na pasta endurecida ocasionada pela baixa presença de cimento não hidratado em sua composição. Entretanto, observou-se uma redução desse parâmetro no traço T5 (com substituição de $11,7 \%$ de cimento) em relação ao TR. Isso pode ser explicado pelo efeito filer que a LRC-S causa na mistura, preenchendo os vazios e ocasionando um efeito contrário à adição da borracha.

Contudo, nenhum dos valores obtidos estão de acordo com o limite máximo de absorção, média ou individual, proposto pela norma ABNT NBR 6136 [24], de 10\% e 12\% respectivamente, como pode ser observado na Figura 13. Foram necessários, então, no estudo da validação a seguir, reformulações na produção. O tempo de vibração e compactação dos tijolos foi dobrado, a fim de diminuir a porosidade de forma a reduzir a absorção para que atendam as normas em questão.

\subsection{Validação das porcentagens de substituição}

Partindo dos resultados obtidos na análise experimental, foram definidos três traços para validação dos resultados. Como a LRC-S não teve efeitos significativos, ela foi mantida constante a uma taxa de substituição do cimento em $15 \%$. Foi definido $8 \%$ como limite superior de substituição do agregado por borracha e $0 \%$ para o limite inferior. Foi realizado também um traço intermediário com $4 \%$ de substituição, além do traço de referência (sem resíduos), conforme Tabela 9.

Tabela 9: Traço dos materiais.

\begin{tabular}{ccccccc}
\hline Traço & LRC-S $(\%)$ & $\begin{array}{c}\text { Borracha } \\
(\boldsymbol{\%})\end{array}$ & $\begin{array}{c}\text { Cimento } \\
(\mathbf{k g})\end{array}$ & $\begin{array}{c}\text { LRC-S } \\
(\mathbf{K G})\end{array}$ & $\begin{array}{c}\text { Areia } \\
(\mathbf{k g})\end{array}$ & $\begin{array}{c}\text { Borracha } \\
(\mathbf{k g})\end{array}$ \\
\hline TR* $^{*}$ & 0 & 0 & 1 & 0 & 12 & 0 \\
\hline T1* $^{*}$ & 15 & 0 & 0.85 & 0.15 & 12 & 0 \\
\hline T2* $^{*}$ & 15 & 4 & 0.85 & 0.15 & 11.78 & 0.22 \\
\hline T3* $^{*}$ & 15 & 8 & 0.85 & 0.15 & 11.55 & 0.45 \\
\hline
\end{tabular}

Os resultados médios de resistência à compressão simples ao longo das idades estão apresentados na Figura 14. Nota-se que já nos 3 dias de idade os tijolos já apresentaram grande parte de sua resistência, conforme já observado anteriormente. Percebe-se também que houve uma perda de $36 \%$ da resistência do traço TR* para o T1* com substituição apenas do cimento por $15 \%$ de LRC-S, no entanto, ainda atendendo a NBR 6136 [24]. Essa perda de resistência pode ser justificada pela capacidade aglomerante insuficiente da LRC-S em maiores taxas de substituição do cimento [19]. Ressalta-se ainda que na análise experimental anterior, o T5 com 11,7\% de LRC-S apresentou resistências superiores ao traço de referência TR, além de revelar que a LRC-S não possui efeitos significativos se comparados com a borracha. Assim adotou-se uma porcentagem superior de LRC-S para o estudo de validação. 


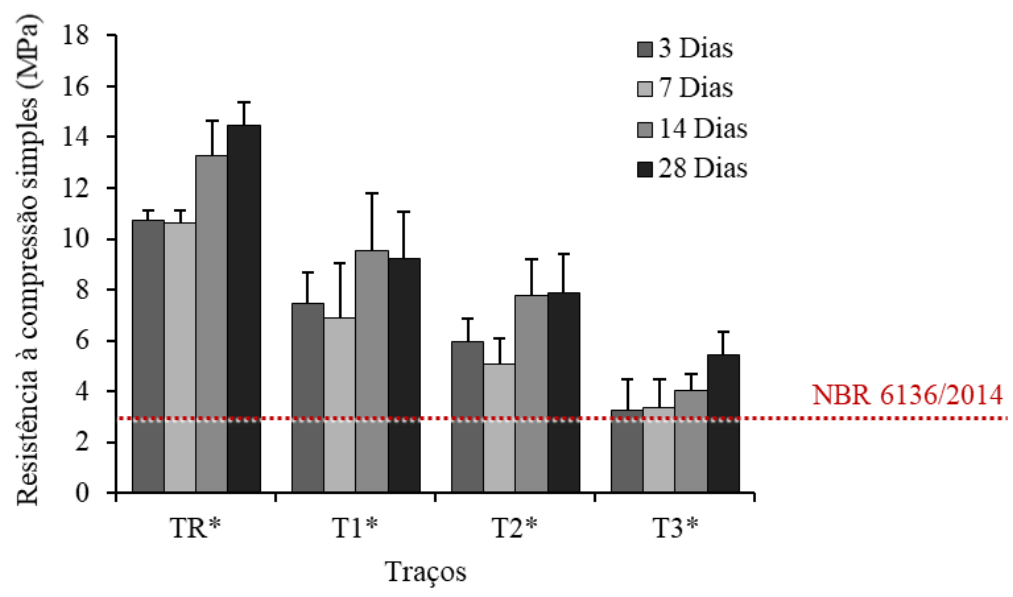

Figura 14: Resistência à compressão dos tijolos aos 3, 7, 14 e 28 dias.

Nota-se também, pela Figura 14, que conforme se aumentou o teor de substituição do agregado por borracha, nos traços T2* e T3*, ocasionou a redução da resistência à compressão, indo ao encontro dos resultados já obtidos. Nos traços TR*, T1* e T2* houve uma perda de resistência aos 7 dias ao analisar apenas a média dos resultados, porém, ao considerar o desvio padrão nota-se que os valores estão semelhantes aos obtidos com 3 dias, não havendo nem ganhos e nem perdas significativas.

Partindo do equacionamento apresentado anteriormente na Tabela 5 obteve-se o gráfico da Figura 15, que representa a curva aos 28 dias para resistência à compressão dos tijolos de concreto com LRC-S e borracha, e os pontos obtidos para validação dos resultados. Salienta-se que foi mantido constante em $15 \%$ a porcentagem de substituição do cimento por LRC-S, pois de acordo com a análise anterior, apenas a borracha tem efeito significativo.

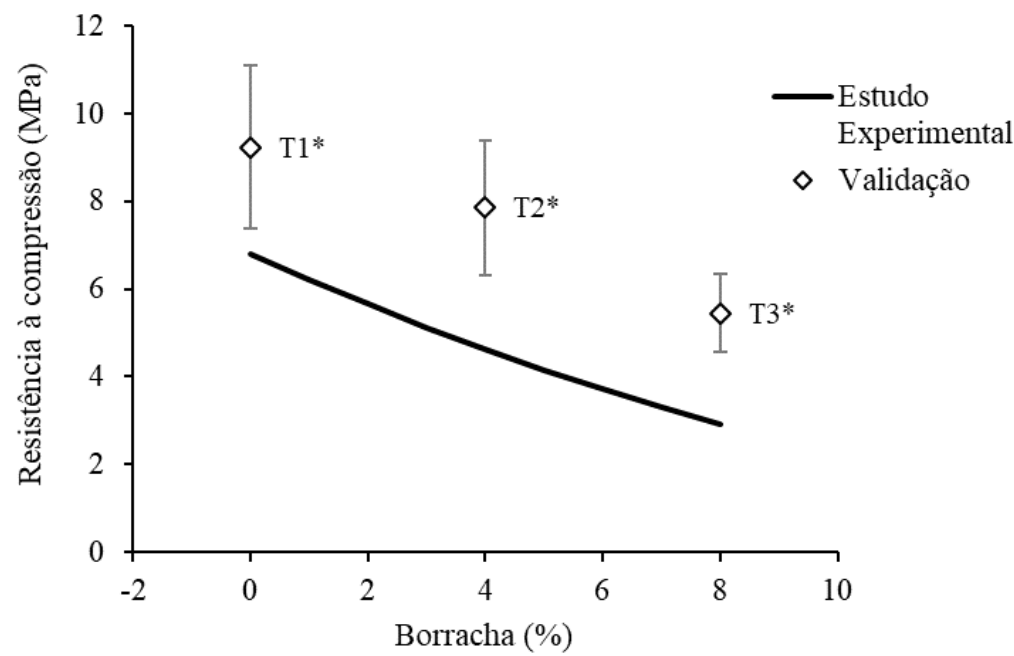

Figura 15: Comparação entre a curva obtida com o Estudo Experimental e os pontos para validação.

Analisando a Figura 15 pode-se perceber que, na validação dos resultados, as resistências dos tijolos mantiveram a tendência dos tijolos do estudo experimental, porém com valores superiores e atendendo o limite inferior de $3 \mathrm{MPa}$ conforme recomenda a ABNT NBR 6136 [24]. Esse aumento da resistência pode ser explicado pela diferença granulométrica do agregado utilizado e pelo grau de vibração imposto pela mesa vibratória, que, para a validação, foram diferentes daqueles empregados no estudo experimental, já atendendo as modificações sugeridas nesta pesquisa.

Os resultados médios de absorção de água estão apresentados na Figura 16. Pode-se perceber que não houve grande variação entre os traços TR*, T1* e T2*, e ambos atenderam o limite de $10 \%$ da ABNT NBR 6136 [24]. Com relação ao T3* tem-se que ele apresentou uma maior absorção, que pode ser explicada pela 
maior porcentagem de substituição do agregado por borracha, porém, os valores individuais não ultrapassaram os $12 \%$ recomendados pela ABNT NBR 6136 [24].

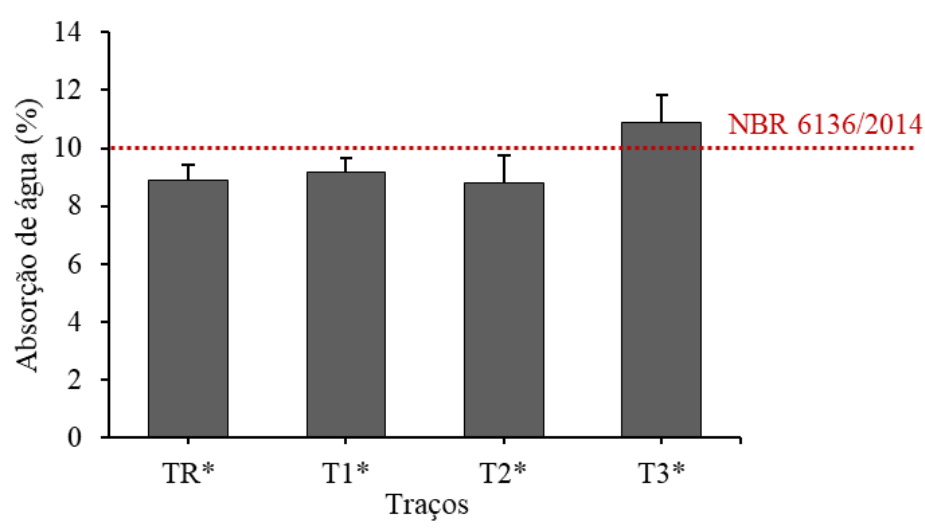

Figura 16: Absorção de água dos tijolos para validação dos resultados.

Com relação ao modelo apresentado no estudo experimental para a absorção de água aos 28 dias, temse que a curva gerada não apresentou a mesma tendência dos pontos da validação, conforme Figura 17. No entanto, a absorção média dos traços ficou dentro dos limites estabelecidos pela ABNT NBR 6136 [24] e NBR 8491 [23].

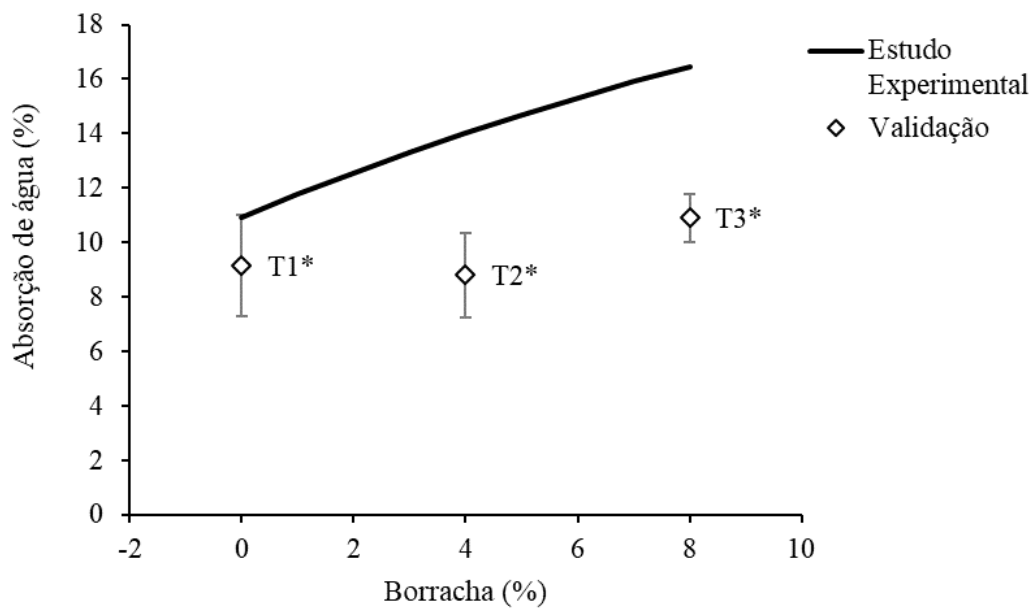

Figura 17: Comparação entre a curva de absorção de água obtida com o Estudo Experimental e os pontos para validação.

Após as análises observou-se que todos os traços da validação atenderam as recomendações acerca da resistência à compressão e absorção de água, reafirmando a viabilidade de se utilizar a LRC-S e o granulado de borracha de pneu. Foi possível perceber também que quanto maior a porcentagem de borracha, menor será a resistência à compressão e maior será a absorção de água, sendo que o limite de substituição da borracha é dependente do agregado empregado e das condições de moldagem, bem como do traço utilizado.

Com relação ao uso da LRC-S em substituição parcial ao cimento, juntamente com a borracha, tem-se que a porcentagem de LRC-S não apresenta efeitos significativos. Desse modo, é possível reduzir a quantidade de cimento, que é a matéria prima de maior valor agregado da produção dos tijolos, sem haver prejuízos de resistência à compressão e absorção de água.

Tem-se, então, que o traço T2*, com $4 \%$ de borracha e $15 \%$ de LRC-S, pode ser considerado com valores ótimos de substituição, apresentando 7,9 MPa de resistência e 8,8\% de absorção média. O T2* atende aos limites estabelecidos pelas normas NBR 6136 [24], NBR 8491 [23] e NBR 7170 [22] e apresenta maiores percentuais de resíduos. Pode-se afirmar, então, que a utilização de tijolos de concreto com resíduo para vedação é viável tecnicamente, de forma a diminuir o volume de resíduos descartados e ainda atender aos critérios exigidos pelas normas. 


\section{CONCLUSÕES}

Foi possível perceber, pelo tema em estudo, que ainda há uma lacuna quanto a utilização da borracha de pneu e da lama residual do concreto para a confecção de tijolos. A utilização desses materiais no processo produtivo de um material de construção poderá não só reduzir o volume de resíduos sólidos gerados, mas também a demanda por agregados naturais e cimento Portland, modificando diretamente a quantidade de recursos naturais e energéticos consumidos.

A Metodologia de Superfície de Resposta (MSR) se mostrou eficiente para os objetivos propostos, permitindo verificar os efeitos dos resíduos na resistência à compressão e absorção de água dos tijolos. Após a validação do estudo foi possível reafirmar os efeitos da borracha nos tijolos, mostrando haver uma tendência na diminuição da resistência conforme se aumenta o teor de substituição do agregado.

Obteve-se também o traço T2* como traço ótimo, com $4 \%$ de borracha e $15 \%$ de LRC-S, em substituição ao agregado e ao cimento, respectivamente. $\mathrm{O}$ traço atende os limites tanto para resistência à compressão, de $3 \mathrm{MPa}$, quanto para absorção de água, de 10\%, da NBR 6136 [24]. No entanto, o limite de substituição pode variar de acordo com o traço adotado, sendo que um traço rico em cimento possibilitaria substituições de maiores porcentagens.

Por fim pode-se destacar a importância da análise do uso da borracha em tijolos de concreto, pois ela poderá causar uma diminuição da resistência à compressão em até $92 \%$. Em contrapartida, o uso da LRC-S em proporções adequadas poderá acarretar um aumento de até $13 \%$ da resistência. Dessa forma, é possível obter traços com porcentagens dos dois resíduos que satisfazem as normativas.

\section{AGRADECIMENTOS}

Às empresas Brasmix, Vipal, GS Pré-Moldados e ConstruCastro Materiais e Pré-Moldados por fornecer os materiais, equipamentos, local e mão-de-obra para a fabricação dos tijolos de concreto. A Fundação de Amparo à Pesquisa do Estado de Goiás - FAPEG pelo apoio financeiro. Aos responsáveis pelos Laboratórios dos cursos de Química, Geografia, Engenharia Civil e de Minas por auxiliarem na execução dos ensaios desenvolvidos neste estudo.

\section{BIBLIOGRAFIA}

[1] CARELI, E., A resolução CONAMA n. 307/2002 e as novas condições para a gestão dos resíduos de construção e demolição, Dissertação de M.Sc., Centro Estadual de Educação Tecnológica Paula Souza, São Paulo, SP, Brasil, 2008.

[2] FREIRE, W. J., BERALDO, A. L., Tecnologias e materiais alternativos de construção. [S.1.]: Unicamp, 2003. v. 1.

[3] MONTEIRO, J. H. P. et al. "Gestão integrada de resíduos sólidos: manual gerenciamento integrado de resíduos sólidos", In: Gestão integrada de resíduos sólidos: manual gerenciamento integrado de resíduos sólidos. [S.1.]: IBAM, 2001.

[4] LAGARINHOS, C. A. F.; TENÓRIO, J. A. S. "Tecnologias utilizadas para a reutilização, reciclagem e valorização energética de pneus no brasil”, Polímeros, SciELO Brasil, v. 18, n. 2, p. 106-118, 2008.

[5] FIORITI, C. F. Avaliação de compósitos de concreto com resíduos de borracha na produção de blocos para alvenaria, Tese de D.Sc., Faculdade de Engenharia de Ilha Solteira da Universidade Estadual Paulista"Julio de Mesquita Filho.", 2002.

[6] FIORITI, C. F., INO, A., AKASAKI, J. L., "Análise experimental de blocos intertravados de concreto com adição de resíduos do processo de recauchutagem de pneus", Acta Scientiarum. Technology, Universidade Estadual de Maringá, v. 32, n. 3, 2010.

[7] SILVA, L. S., MOURA, J. R., COSTA, M. C. B., GOMES, L. G." Concreto com borracha de recauchutagem de pneu para uso em pavimentação de baixo tráfego", Revista Matéria, v. 24, n.2, 2019.

[8] ROMUALDO, A. et al. "Pneus inservíveis como agregados na composição de concreto para calçadas de borracha", Cleaner Production Initiatives and Challenges for a Sustainable World”. São Paulo, Brasil, 2011.

[9] BENSON, C. "Using shredded scrap tires in civil and environmental construction", Resource Recycling, Resource Recycling Inc, v. 14, p. 71-71, 1995.

[10] WANG, R., HE, X., LI, Y. "Evaluation of microcracks in the interfacial transition zone of recycled rubber concrete", Structural Concrete, Internacional Federetion for Structural Concrete, v.20, p. 1684-1694, 2019. 
[11] SIDDIKA, A., MAMUN, Md. A. A., ALYOUSEF, R., AMRAN, Y. H. M., ASLANI, F. ALABDULJABBAR, H. Properties and utilizations of waste tire rubber in concrete: A review, Conctruction and Building Materials, Elsevier, v. 224, p. 711-731, 2019.

[12] THOMAS, B. S., GUPTA, R. C. "A comprehensive review on the applications of waste tire rubber in cement concrete", Renewable and Sustainable Energy Reviews, Elsevier, v. 54, p. 1323-1333, 2016.

[13] SEALEY, B., PHILLIPS, P. S., HILL, G. "Waste management issues for the uk ready-mixed concrete industry", Resources, Conservation and Recycling, Elsevier, v. 32, n. 3, p. 321-331, 2001.

[14] VIEIRA, L. d. B. P., FIGUEIREDO, A. D. de. "Resíduos da concreteira: o aproveitamento do problema", Concreto \& Construções, São Paulo, v. 41, n. 71, p. 41-45, 2013.

[15] PAULA, H., ILHA, M. "Quality of concrete plant wastewater for reuse", Revista IBRACON de Estruturas e Materiais, SciELO Brasil, v. 7, n. 3, p. 349-366, 2014.

[16] TSIMAS, S., ZERVAKI, M. "Reuse of waste water from ready-mixed concrete plants", Management of Environmental Quality: An International Journal, Emerald Group Publishing Limited, v. 22, n. 1, p. 7-17, 2011.

[17] SILVA, D. O. F. d. Reaproveitamento de lamas residuais do processo de fabricação do concreto. Tese de D.Sc., Universidade de São Paulo, 2016.

[18] ERMCO. Guidance on Concrete Wash Water in the European Ready Mixed Concrete Industry. 2006. Disponível em: <http://www.ermco.eu/document/ermco_wash_water_guidance_oct_2006-pdf/>. Acessado em janeiro de 2017.

[19] AUDO, M., MAHIEUX, P.-Y., TURCRY, P. "Utilization of sludge from ready-mixed concrete plants as a substitute for limestone fílers", Construction and Building Materials, Elsevier, v. 112, p. 790-799, 2016.

[20] KOU, S.-c., ZHAN, B.-J., POON, C.-s "Properties of partition wall blocks prepared with fresh concrete wastes", Construction and Building Materials, Elsevier, v. 36, p. 566-571, 2012.

[21] WANG, Q, ZHANG, Y, FANG, Y, ZHANG, Y, WU, F, "Prediction of the mechanical behavior of recycled concrete with fresh concrete waste aggregate", Structural Concrete, Internacional Federetion for Structural Concrete, v. 21, n. 2, p. 761-771, 2020.

[22] ASSOCIAÇÃO BRASILEIRA DE NORMAS TÉCNICAS. NBR 7170: Tijolo maciço cerâmico para alvenaria. Rio de Janeiro, 1983. 4 p.

[23] ASSOCIAÇÃO BRASILEIRA DE NORMAS TÉCNICAS. NBR 8491: Tijolo de solo-cimento - requisitos. Rio de Janeiro, 2012. 5 p.

[24] ASSOCIAÇÃO BRASILEIRA DE NORMAS TÉCNICAS. NBR 6136: Blocos vazados de concreto simples para alvenaria - requisitos. Rio de Janeiro, 2014. 13 p.

[25] SILVA, T. D. et al. "Uso de granulado de borracha em substituição parcial ao agregado miúdo na produção de tijolos ecológicos.”, Revista Matéria, v. 22, n. 4, 2017.

[26] BONFIM, W. B. et al. "Uso de resíduo cimentício como substituto parcial de cimento Portland na produção de tijolos de concreto", In: XV Congreso Latinoamericano de Patología de Construcción y XVII Congreso de Control de Calidad en la Construcción - CONPAT, Chiapas, México, Vol. 1, 2019.

[27] NEVILLE, A. M. Tecnologia do concreto. [S.1.]: Bookman Editora, 2013.

[28] ASSOCIAÇÃO BRASILEIRA DE NORMAS TÉCNICAS. NBR 9935: Agregados- Terminologia. Rio de Janeiro: ABNT, 2011. $12 \mathrm{p}$

[29] ASSOCIAÇÃO BRASILEIRA DE NORMAS TÉCNICAS. NBR NM 248: Agregados - determinação da composição granulométrica. Rio de Janeiro, 2003. 6 p.

[30] EMBRAPA, E. C. N. de Pesquisa de S. Manual de métodos de análise de solo. [S.1.]: Embrapa,1997.

[31] DIAMOND, W. J. Practical experiment designs. [S.1.]: New York: Van Nostrand Reinholds,1989.

[32] CONAGIN, A. "Delineamentos 'compostos centrais ortogonais, rotacionais e divisíveis em blocos', Bragantia, Directory of Open Access Journals, v. 41, n. 1, p. 49-56, 1982.

[33] RODRIGUES, M. I., IEMMA, A. F. Planejamento de experimentos e otimização de processos: uma estratégia sequencial de planejamentos. [S.1.]: Casa do Pão Editora, 2014.

[34] STATSOFT. : Statistica: Statsoft inc.: Data analysis software system p. version 10.0. [S.1.], 2011.

[35] ASSOCIAÇÃO BRASILEIRA DE NORMAS TÉCNICAS. NBR 12118: Blocos vazados de concreto simples para alvenaria. Rio de Janeiro, 2014. 14 p. 
[36] ASSOCIAÇÃO BRASILEIRA DE NORMAS TÉCNICAS. NBR 8492: Tijolo de solo-cimento - análise dimensional, determinação da resistência à compressão e da absorção de água - método de ensaio. Rio de Janeiro, 2012. 4 p.

[37] ASSOCIAÇÃO BRASILEIRA DE NORMAS TÉCNICAS. NBR ISO 7500-1: Materiais metálicos calibração e verificação de máquinas de ensaio estático uniaxial parte 1: Máquinas de ensaio de tração/ compressão - calibração e verificação do sistema de medição da força. Rio de Janeiro, 2016.19 p.

[38] ASSOCIAÇÃO BRASILEIRA DE NORMAS TÉCNICAS. NBR 7211: Agregados para concreto - especificação. Rio de Janeiro, 2009. 12 p.

[39] SADEK, D. M., EL-ATTAR, M. M. "Structural behavior of rubberized masonry walls", Journal of Cleaner Production, Elsevier, v. 89, p. 174-186, 2015.

[40] SILVEIRA, P. M. et al. "Estudo do comportamento mecânico do concreto com borracha de pneu", Revista Matéria, v. 21, n. 2, p. 416-428, 2016.

[41] SHTAYEH, S. M. S. Utilization of waste tires in the production of non-structural Portland cement concrete. Tese de D.Sc., An-Najah National University, 2007.

ORCID

Ruvier Rodrigues Pereira

https://orcid.org/0000-0002-4803-8062

Heber Martins de Paula

https://orcid.org/0000-0002-7066-1408

Walter Batista Bonfim

https://orcid.org/0000-0001-6647-6835

Iandra de Almeida Corrêa e Silva

https://orcid.org/0000-0001-8595-7589

Henrique Senna Diniz Pinto

https://orcid.org/0000-0002-7759-456X 